\title{
Infraestructuras con riesgo en una comarca de la España Atlántica'
}

\author{
Infrastructures with risk in a region of Spain's Atlantic
}

\author{
María Sotelo Pérez² y José Antonio Sotelo Navalpotro ${ }^{3}$
}

\begin{abstract}
RESUMEN
La realidad recogida en la diacronía de las últimas décadas ha sufrido importantes cambios, en el ámbito de los procesos de elaboración y aplicación de la denominada "evaluación de impacto ambiental", si bien, dichas metodologías no han alcanzado un papel fundamental en el propio proceso planificador sino que en no pocos casos, simplemente, se han ido integrando como un elemento más dentro del ámbito de la planificación territorial. En el presente estudio se tiene por objeto conocer, valorar, e interpretar el impacto real, emanado de la aplicación de un modelo de desarrollo de carácter económico y social, donde el medio ambiente o la calidad ambiental, queda relegados a un segundo nivel. Todo ello, cobra mayor relevancia si centramos nuestra mirada en la construcción y ampliación de infraestructuras, en este caso concreto, de carácter vial, en una región especialmente compleja, desde el punto de vista territorial, como es la comarca del Morrazo (Galicia); donde la aplicación de la "evaluación de impacto ambiental" no supone o, por lo menos, no conlleva una intervención concisa y contundente, por parte de los poder públicos, ante la degradación auténtica de los espacios naturales, ni de los ecosistemas existentes y, mucho menos, suponen una actuación, ya no solo en la prevención sino en la restauración y recuperación de dichos ambientes.
\end{abstract}

Palabras clave: Medio ambiente, evaluación de impacto ambiental, comarca, riesgos, impactos.

\begin{abstract}
Throughout the last decades, important progress has been made in the area of the processes of elaboration and application of the so-called "environmental impact assessment", although, these methodologies have not played a fundamental role in the planning process but, simply, they have been integrated as one more element within the scope of territorial planning. The purpose of this study is to know, assess, and interpret the real impact, emanated from the application of a model of economic and social development, where the environment or environmental quality, is relegated to a second level. All this becomes more relevant if we focus our attention on the construction and expansion of infrastructures, in this specific case, of a road nature, in a particularly complex region, from the territorial point of view, such as the Morrazo region (Galicia); where the application of the "environmental impact assessment" does not imply or, at least, does not involve a concise and forceful intervention, by the public authorities, in the face of the authentic degradation of natural spaces, nor of the existing ecosystems and, much less, suppose an action, no longer only in the prevention but in the restoration and recovery of said environments.
\end{abstract}

Keywords: Environment, evaluation of environmental impact, region, risks, impacts. 
Los actuales procesos emanados de la denominada "globalización" poseen características singulares, en el procedimiento de intervención en espacios y territorios específicos. Los cuales, comienzan a ejercer un protagonismo propio, emanado de unas relaciones causa-efecto sumamente complejas, en relación con los denominados "modelos de desarrollo", propiamente dichos. De este modo, en el presente trabajo se pone de manifiesto como el arquetipo más adecuado para corroborar que, efectivamente, nos encontramos con elementos que contribuyen o que entorpecen los progresos en el proceso de desarrollo de territorios concretos como sucede en las denominadas "Rías Baixas", en la Comunidad Autónoma de Galicia. Específicamente, en este estudio nos centramos en la comarca del Morrazo -la de menor extensión de toda Galicia y, sin embargo, una de las más pobladas-; transformada, en las últimas décadas en un eje real de captación y cohesión, tanto poblacional como económica, y, como organizadora del propio espacio $y$, vertebradora de dicho territorio.

Así pues, en el presente estudio se tiene por objeto evidenciar como, en los momentos actuales, lo que se han venido a denominar "riesgos antrópicos", tienen una enorme presencia en el proceso de transformación territorial emanado de la construcción de infraestructuras en el propio Morrazo, tanto con la primera fase de edificación como en la presente ampliación del denominado "corredor". Es por esto por lo que se considera, a la par que se consolida, como un elemento ejemplarizante de cómo la planificación y desarrollo de una infraestructura puede destruir, degradar y esquilmar un ecosistema, a su paso por un determinado territorio, estando en consonancia e, incluso, en pleno cumplimiento con toda la normativa vigente. Remarcando la idea de que ni la Declaración Ambiental ni la Evaluación de Impacto Ambiental logran controlar y, mucho menos detener, los riesgos e impactos, $y$, ya que decir de los daños, originados en un medio físico endeble $y$, sus repercusiones sobre el medio humano y económico, por una amenaza palpable y visible como es el "corredor del Morrazo"; especialmente, cuando estamos centrándonos en la ampliación del llamado puente de Rande -edificado sobre la ría de Vigo y que daba continuidad a la Autopista del Atlántico-, cuyas obras han supuesto la transformación del "corredor" en autovía.

Con todo ello, se pone de manifiesto como el proceso de ampliación del "corredor" como del puente de Rande, suponen un aumento más que exponencial del impacto y de las amenazas sobre el medio natural, pues, ante la inexistencia o, mejor dicho, ante la carencia de figuras de protección, la aprobación del proceso ejecutiro de dichas obras no necesitaron siquiera la elaboración de una Evaluación de Impacto Ambiental en esta fase de ampliación.

\section{Marco teórico}

Todas las decisiones económicas tienen implicaciones ambientales; no se trata de que en ciertos casos existan externalidades, sino que más bien, las "externalidades" impregnan todo el sistema económico. De hecho, las externalidades no son fallos del mercado sino notables éxitos en transferir costes a otros. Todo ello sin olvidarnos que, en general, el mercado no da solución, per se, a los problemas ambientales -generados o no por él- , por muy bien delimitados que estén los derechos de propiedad. Desde esta perspectiva, el equilibrio lo encontramos en los poderes públicos no corrompidos, y en los objetivos ambientales fijados "políticamente". Todo lo relativo a las intervenciones en el medio ambiente se fija desde fuera de la geografía o de la economía. Podemos preguntarnos, de esta manera ¿cuál es la forma más económica de conseguir que la norma ambiental se cumpla? 
La evaluación de impacto ambiental se entiende que es un procedimiento que, sin lugar a dudas, remarca un cierto significado que trasciende a la mera caracterización jurídica, y administrativa, ya que en el desarrollo de sus determinadas etapas, suelen interponerse e influir fuertes implicaciones de carácter político (afirmación sustentada sobre la conceptualización de la evaluación de impacto ambiental como un medio procedimental por el que se impulsa la realización de una serie de estudios y análisis relativos al alcance que las acciones, planes y proyectos determinados tienen sobre el medio ambiente). En la presente investigación, nos aproximamos desde la aplicación del método hipotético deductivo, al conocimiento de las consecuencias derivadas del desarrollo de diversas infraestructuras, con consecuencias no paliadas con la aplicación de la Evaluación de Impacto Ambiental (ver Figuras N¹ y N²).

Si nos detenemos, brevemente, en el procedimiento de la misma, en el Ordenamiento jurídico aplicable a nuestro caso de estudio, señalar que en España la experiencia de la evaluación de impacto ambiental (como método para incorporar dentro de los estudios de decisión, las circunstancias ambientales), se consolida por medio de la aprobación de una serie de desarrollos normativos surgidos originariamente en el ámbito comunitario, a través de la Directiva 85/377/CEE de 27 de junio de 1985; ésta establece que «no se aplicará a los proyectos detallados adoptados mediante un acto legislativo nacional específico, dado que los objetivos perseguidos por la presente Directiva, incluido el objetivo de la disponibilidad de informaciones, se consiguen a través del procedimiento legislativo»(art.1.5), y que posteriormente sería transpuesta mediante el Real Decreto Legislativo 1302/86, de 28 de junio, y, el Real Decreto 1131/88, de 30 de septiembre, al seno del derecho interno español.

En este sentido, dentro del ordenamiento jurídico español diferenciamos dos niveles:

Figura No 1.

Marco Legislativo Comunitario y Estatal.

\begin{tabular}{|c|c|}
\hline ivel legislativo Com & \\
\hline \multicolumn{2}{|c|}{$\begin{array}{l}\text { tiva 85/337/CEE, del Consejo, de } 27 \text { de junio de 1985, relativa a la evaluación de las reper- } \\
\text { s de determinados proyectos públicos y privados sobre el medio ambiente. }\end{array}$} \\
\hline \multicolumn{2}{|c|}{$\begin{array}{l}\text { La Directiva 97/11/CE del Consejo, de } 3 \text { de marzo de 1997, por la que se modifica la Directiva } \\
85 / 337 / \text { CEE relativa a la evaluación de las repercusiones de determinados proyectos públicos y } \\
\text { privados sobre el medio ambiente. }\end{array}$} \\
\hline \multicolumn{2}{|c|}{$\begin{array}{l}\text { Directiva 2001/42/CE, del Parlamento Europeo y del Consejo, de } 27 \text { de junio de 2001, relativa a la } \\
\text { evaluación ambiental de los efectos de determinados planes y programas en el medio ambiente } \\
\text { (esta directiva no regula lo concerniente a los proyectos). }\end{array}$} \\
\hline \multicolumn{2}{|c|}{$\begin{array}{l}\text { La Directiva 2011/92/UE del Parlamento Europeo y del Consejo, de } 13 \text { de diciembre de 2011, rela- } \\
\text { tiva a la evaluación de las repercusiones de determinados proyectos públicos y privados sobre } \\
\text { el medio ambiente (por medio de esta Directiva 2011/92/UE, se derogó una serie de directivas, la } \\
\text { Directiva } 85 / 337 / C E E \text {, la Directiva 97/11/CE, así como los artículos } 3 \text { de la Directiva 2003/35/CE } \\
\text { y el } 31 \text { de la Directiva 2009/31/CE. }\end{array}$} \\
\hline
\end{tabular}


Tras todas ellas surgiría la Directiva 2014/52/UE del Parlamento Europeo y del Consejo de 16 de abril de 2014 por la que se modifica la Directiva 2011/92/UE, relativa a la evaluación de las repercusiones de determinados proyectos públicos y privados sobre el medio ambiente.

\begin{tabular}{|l|l|l} 
El nivel legislativo Estatal & Las normas Europeas anteriormente mencionadas, fueron tras- \\
\hline
\end{tabular} (en la que nos encontramos) puestas a nuestro derecho interno mediante las siguientes normas:

El Real Decreto Legislativo 1302/1986, de 28 de junio, de evaluación de impacto ambiental, y el Real Decreto 1131/1988, de 30 de septiembre, por el que se aprueba el Reglamento para la ejecución del Real Decreto Legislativo 1302/1986, de 28 de junio, de evaluación de impacto ambiental (Vigente hasta el 12 de Diciembre de 2013).

La Ley 6/2001, de 8 de mayo, de modificación del Real Decreto legislativo 1302/1986, de 28 de junio, de evaluación de impacto ambiental (que se encontraría vigente hasta el 27 de Enero de 2008).

Progresivamente el Real Decreto Legislativo 1302/86, de 28 de junio, quedaría derogado por el Real Decreto Legislativo $1 / 2008$, de 11 de enero, por el que se aprueba el texto refundido de la Ley de Evaluación de Impacto Ambiental de proyectos, y este a su vez por la Ley 21/2013, de 9 de diciembre, de evaluación ambiental

Respecto al Real Decreto 1131/1988, de 30 de septiembre, por el que se aprueba el Reglamento para la ejecución del Real Decreto Legislativo 1302/1986, de 28 de junio, de evaluación de impacto ambiental (Vigente hasta el 12 de Diciembre de 2013), mostrar como este quedaría a su vez derogado por la letra c) del número 1 de la disposición derogatoria única de la Ley 21/2013, de 9 de diciembre, de evaluación ambiental

Finalmente, nos encontramos con la Ley 9/2018, de 5 de diciembre, por la que se modifica la Ley 21/2013, de 9 de diciembre, de evaluación ambiental, la Ley 21/2015, de 20 de julio, por la que se modifica la Ley 43/2003, de 21 de noviembre, de Montes y la Ley 1/2005, de 9 de marzo, por la que se regula el régimen del comercio de derechos de emisión de gases de efecto invernadero.

Fuente: Elaboración propia.

En resumen, la legislación de Evaluación de Impacto Ambiental quedaría temporalmente predispuesta de la forma siguiente:

Figura № 2 .

Marco Legislativo Autonómico y Convenios Internacionales.

\begin{tabular}{|l|l|}
\hline $\begin{array}{l}\text { El nivel legislativo Autonómico } \\
\text { (en el que se aprecia) }\end{array}$ & Comunidad Autónoma de Galicia \\
\hline Ley 1/1995, de 2 de enero, de Protección Ambiental de la Comunidad Autónoma de Galicia. \\
\hline Decreto 327/1991, de 4 de octubre, de evaluación de efectos ambientales para Galicia. \\
Orden de 15 de marzo de 2012, conjunta de las consellerías de Medio Ambiente, Territorio e \\
Infraestructuras y del Medio Rural y del Mar, sobre régimen de la evaluación ambiental de los \\
establecimientos de acuicultura en la parte litoral de la zona terrestre.
\end{tabular}


La trascendencia de los Convenios de carácter Internacional refrendados

y/ o ratificados por el Reino de España.

Convenio sobre evaluación del impacto en el medio ambiente en un contexto transfronterizo, hecho en Espoo, en 1991.

Protocolo sobre Evaluación Estratégica del Medio Ambiente de la Convención sobre la Evaluación del Impacto Ambiental en un Contexto Transfronterizo, firmado en Kiev en 2003

Protocolo de Actuación entre el Gobierno del Reino de España y el Gobierno de la República Portuguesa de aplicación en las Evaluaciones Ambientales de Planes, Programas y Proyectos con efectos transfronterizos, de 2008.

Fuente: Elaboración propia.

Lo anteriormente expuesto se ve matizado por la distribución Competencial de la Evaluación de Impacto Ambiental; actualmente, en lo concerniente al nivel estatal, la Ley 21/2013, de 9 de diciembre, de evaluación ambiental establece en su preámbulo que «La presente ley se asienta en la competencia exclusiva del Estado en materia de legislación básica sobre protección del medio ambiente, sin perjuicio de las facultades de las comunidades autónomas de establecer normas adicionales de protección (artículo 149.1.23. a de la Constitución)», concentrando en su articulado el "régimen jurídico de la evaluación de programas, planes y proyectos", y habilitando un acervo de preceptos legales comunes que acercarían y favorecerían la práctica efectiva de sendas regulaciones. En lo relativo a las Comunidades Autónomas reseñar que estas, debido a que detentan "Las funciones atribuidas por esta ley al órgano ambiental y al órgano sustantivo, en cuanto a la tramitación de los distintos procedimientos, corresponderán a los órganos que determine la legislación de cada comunidad autónoma cuando se trate de la evaluación ambiental de planes, programas o proyectos que deban ser adoptados, aprobados o autorizados por las comunidades autónomas o que sean objeto de declaración responsable o comunicación previa ante las mismas»(artículo 11.2), por lo que cada Comunidad Autónoma poseen sus oportunas leyes en la materia ${ }^{4}$.

\section{Antecedentes}

Tras lo anteriormente expuesto señalar que el riesgo y las infraestructuras, desde una perspectiva de la evaluación ambiental, nos muestra como a lo largo de las últimas décadas se han pro-

\footnotetext{
A este respecto destacar aquellas consideraciones que nos sirven para ilustrarnos en la materia, en primer lugar el fragmento recogido en las enmiendas introducidas por el Partido Nacionalista Vasco al proyecto de ley de modificación del Real Decreto Legislativo 1302/1986 (que procedían del Real Decreto Ley 9/2000, del 6 de octubre), se mostraba como «el TC, consideraba a la evaluación de impacto ambiental no es un acto de ejecución o gestión ambiental, sino un trámite previo que se integra en la aprobación final del proyecto, siendo conforme al orden constitucional, la atribución de las competencias de evaluación del impacto ambiental a las administraciones (se refería a la Administración del Estado) que ostenten las competencias sustantivas en relación a los proyectos de obras e instalaciones sometidas a control medioambiental. En definitiva que la competencia sustantiva atrae la competencia sobre gestión del medio ambiente». En segundo lugar reseñamos la importancia que el Tribunal Constitucional concede al Medio Ambiente y su valoración, mostrándonos como «La evaluación de impacto ambiental no puede caracterizarse, por consiguiente, como ejecución o gestión en materia de medio ambiente. La finalidad, contenido y efecto de la norma básica estatal conduce a que todas las Administraciones públicas valoren el medio ambiente cuando ejercen sus competencias sobre cualquiera de las obras, instalaciones u otras actividades de su competencia. Muchas de esas obras, instalaciones y actividades forman parte de materias sometidas por la Constitución y los Estatutos de Autonomía a reglas específicas de reparto de competencias, que son títulos que por su naturaleza y finalidad atrae a la de medio ambiente, cuyo "carácter complejo y multidisciplinario afecta a los más variados sectores del ordenamiento" (STC 64/1982, fundamento jurídico 30)» (Sentencia del Tribunal Contitucional 13/1988, de 22 de enero).
} 
ducido notables avances, tanto desde el punto de vista de la investigación como de la práctica. Sin embargo, estas metodologías, aunque desempeñan un papel importante, no dejan de ser un componente más, en el proceso planificador. Las investigaciones en curso no permiten explicar y valorar, completamente, hasta qué punto las denominadas buenas prácticas están siendo seguidas y cuáles son sus consecuencias, a la hora de llevar a la práctica los planes, los programas y los proyectos (en nuestro caso de estudio, las infraestructuras). En la mayoría de los casos, la evaluación de impacto ambiental, tal y como lo recogen las investigaciones del "Mánchester EIA Centre", en trabajos referentes al Reino Unido, como los de Kobus, D. and Lee, N. (1993), Wood, C. y Jones, C.E. (2011) o la Reviewing Environmental Impact Statements. Entre otros. En ellas, se pone de manifiesto cómo a la hora de relacionar el riesgo con las obras públicas, los cambios más significativos para los proyectos se encuentran en las fases de inicio de la aplicación de la Evaluación de Impacto Ambiental (EAI), fenómeno que contrasta la realidad, ya que debería llevarse a cabo al final del propio proceso, en el desarrollo y ejecución del proyecto. De esta forma, tal y como recoge Roy, B (2015), en las etapas principales de la EIA, a saber: la inicial que incluye el "screening" y el "scoping", la intermedia (en la que se incluyen los estudios y valoración de los impactos) y la final, en la que se recogen las distintas alternativas, y la decisión de aceptar o rechazar la propuesta; debe ser en la tercera en la que mediante métodos de decisión multicriterio, debería valorarse la importancia de los riesgos medioambientales con los que se va a encontrar la práctica del propio proyecto (cuestiones que no siempre se llevan a la práctica; de hecho, no siempre tienen en cuenta la incertidumbre en la predicción de impactos, cuestión que resta valor y credibilidad a la evaluación ambiental, tal y como recogen en su investigación Barton, J.R. et alii, 2016).

Las cuestiones anteriores, a la hora de aplicar estos métodos en la Evaluación de Impacto Ambiental, han sido desarrolladas en investigaciones como las de Simona, J. (1990), Vincke, PH. (2002), Phaneuf, Y (2010), Kleinschmidt, V (2013) o HSU, A. (2014), entre otros. En este último, y nos ha sido de gran interés en la presente investigación, al tratar de la protección del suelo como recurso, refiriéndose de forma concreta a la planificación de carreteras, sirviendo como ejemplo el estudio de caso del Estado de North Rhine-Westfalia, en Alemania. Destaca, de forma especial, necesidad de proteger el suelo, los recursos naturales y los antrópicos a partir del desarrollo y puesta en práctica de estándares y criterios de calidad, superando de esta manera la merma que suponen los descuidos que en ocasiones generan notabilísimos impactos ambientales.

Y es que, la evaluación de los impactos significativos es, por lo general, la "caja negra" del proceso de Evaluación de Impacto Ambiental; sin embargo, como señala Parkin, J. (1993), los efectos sociales sobre las decisiones en la asignación de los recursos, a la hora de valorar la dualidad "riesgos e infraestructuras" son demasiado importantes para que puedan tomarse las decisiones a partir de un procedimiento opaco y libre de escrutinio político. Todo ello en concurrencia con investigaciones en las que se ponen de manifiesto las dificultades de transferencia directa de los principios de la Evaluación de Impacto Ambiental, tal y como se aplican -cuando esto es así, se llevan a la práctica- a los proyectos en curso, como los estudiados en nuestra investigación, en la que se pone de manifiesto que no es posible cuantificar los impactos que van a ocurrir como consecuencia de la implementación y puesta en práctica de las infraestructuras viales. Estas y otras cuestiones relacionadas con lo mismo, se recogen en el Informe de MAPFRE (2003), en el estudio de Dancey, R y Lee, N (2003) o en el trabajo de la United Nations Economic Comisión for Europe (2012), entre una gran variedad de bibliografía al uso, punto de partida de nuestro presente estudio. 


\section{Metodología e interpretación del territorio}

Partiendo de la premisa fundamental de la importancia que cobra el análisis y valoración de las repercusiones emanadas de la puesta en funcionamiento y la ejecución de infraestructuras, como eje primigenio de la implantación de modelos de desarrollo territorial (en este caso concreto, con el objeto de vertebrar el espacio y mejorar la conectividad regional), la justificación del presente estudio tiene su origen en la hipótesis inicial de la evolución de los procesos de transformación de los modelos de desarrollo tradicionales hacia otros que podemos denominar "endógenos", en un territorio como las denominadas "Rías Baixas" gallegas; donde no solo genera externalidades de carácter positivo sino que propicia la expansión de externalidades negativas que dan lugar a enormes desequilibrios y brechas territoriales, estando todas ellas en estrecha relación con las consecuencias ambientales fruto de los cataclismos ecológicos, tales como los incendios forestales o el hundimiento de barcos petroleros, como es el caso concreto del Prestige. Por ello, a partir del uso y empleo del método científico hipotético deductivo, en este trabajo se parte de un estudio preliminar del contexto territorial en el que se encuadran las obras de ampliación y mejora del denominado "corredor del Morrazo" para, posteriormente, ir valorando e interpretando el impacto real de dichas infraestructuras en el medio físico, humano y económico de la comarca del Morrazo; todo ello, haciendo especial mención a la instrumentación actualmente en uso como es "evaluación de impacto ambiental" y su incidencia en el caso concreto que nos acontece, que en unas ocasiones se buscan excusas para no aplicar la misma, y en otras, simplemente, no se lleva a la práctica.

Así pues, en el proceso de evaluación de la importancia que tienen los modelos de desarrollo para la resolución de conflictos e impedimentos tanto económicos como sociales y ecológicos que originan los riesgos antrópicos -sin olvidar los naturales y tecnológicos-, así como influye y repercute la declaración de impacto ambiental en el propio territorio. Así pues, la metodología de estudio que ha marcado el presente trabajo está delimitada por la propia hipótesis inicial, y, su intencionalidad es la de responder a las demandas y necesidades de los agentes, favoreciendo la intervención en el propio territorio de manera, no solo eficaz, sino eficiente.

Para la ejecución de este estudio se ha realizado una importante labor de trabajo de campo (a través del cual se no solo se ha ido interpretando y valorando la compleja realidad del propio territorio sino que se ha generado una cuantiosa, a la par que interesante, base fotográfica), llevado a cabo desde el año 2015 hasta la actualidad, donde se ha ido supliendo las carencias documentales propias del territorio llevado a estudio, así como complementando el trabajo de gabinete, nutrido de fuentes documentales primarias y secundarias, donde el acceso web ha sido notable. Igualmente, junto con el amplio amalgama de documentación obtenido de las redes telemáticas (y su posterior valoración y análisis), los trabajos cartográficos, así como la Declaración de Impacto Ambiental llevados a cabo por la empresa ICEACSA, han sido supuesto un gran aporte de información sobre los procesos de ensanche y cambio de las infraestructuras del "corredor". Todo ello, se ha consolidado como eje inicial del análisis, valoración e interpretación de la realidad que acontece la ejecución de unas obras de tales dimensiones como son las llevadas a cabo con la ampliación del "corredor del Morrazo", así como conocer los riesgos, peligros e impactos generados, tanto en el medio físico como humano y económico, en un territorio complejo como es el de las "Rías Baixa" gallegas. 


\section{Los espacios de riesgo en los contextos territoriales}

Lo señalado nos muestra cómo aproximarnos a la compleja realidad de los "riesgos" vinculados a los procesos de "desarrollo" supone valorar los nuevos paradigmas ecológicos que coadyuvan a comprender la compleja evolución de las Ciencias Sociales, en general, y de la Geografía y la Economía, en particular. Para economistas como Galbraith o Sen es necesario reconducir hoy la disciplina económica a la función que la vio nacer, es decir, a tratar de garantizar el futuro bienestar basándose en la racionalidad de las políticas y de los comportamientos presentes (Sotelo Navalpotro, J.A., 2008).

La ejecución de obras públicas de tales dimensiones como son las llevadas a cabo en el llamado "corredor del Morrazo", se tornan imprescindibles en los procesos vertebradores del territorio, constituyéndose como una de las bases fundamentales de los modelos de desarrollo, si bien, los riesgos e impactos que de ellos se desprenden, así como las amenazas y daños que se generan, tanto en el medio natural, a corto plazo, como en el medio humano y los cambios económicos que conllevan, a medio y largo plazo, suponen una enorme presión sobre dicho espacio y sobre el proceso evolutivo del desarrollo territorial. Remarcando en todo momento que los procesos acaecidos en los momentos presentes tienen un más que sustancial incidencia en el ámbito local; pues la vertebración territorial genera articulaciones locales que transforman, de manera radical $y$, sin capacidad de retroceso, de las áreas locales (modificando, no solo su medio físico, sino sus relaciones sociales, productivas, culturales, etc.).

Es en este contexto en el que la inserción de las infraestructuras viales, de enormes dimensiones -concentradas en el paisaje-, como el caso que nos acontece, constituye un desafío para la gestión del paisaje, en general, y para la política territorial en particular. La integración paisajística de las intervenciones humanas y de las construcciones constituye una demanda social y, de forma reciente, administrativa, que, sin embargo, adolece de planteamientos teóricos sólidos, así como de desarrollos metodológicos específicos. De este modo, el paisaje es concebido como una cualidad intrínseca del territorio, sobre el cual, dichas edificaciones humanas suponen una enorme presión, tanto cuantitativa como cualitativa, que acaban, no solo transformando por completo la realidad de ese territorio, sino degradándolo a niveles completamente exacerbados, en muchos casos, hasta la propia destrucción de dicho paisaje, eliminando por completo la identidad del mismo. Todo ello afecta especialmente a los ámbitos periurbanos que acaban siendo "absorbidos", por las grandes concentraciones urbanas, que expanden sus límites alrededor de dichas infraestructuras viales, inicialmente, en hábitat dispersos y que, finalmente, terminan por concentrarse (propiciado, en muchos casos, por procesos especulativos). De este modo, en nuestra área de estudio, el paisaje natural se nos presenta como un componente de gran valor en áreas urbanas en expansión y, muy pronto, en proceso de congestión, que aporta un enorme potencial de componentes tanto físicos como biológicos, emanados del ámbito rural. Por toro ello, descender a la escala comarcal se torna fundamental, a la hora de conocer y valorar la realidad geográfica del impacto y los riesgos emanados de unas obras de tales envergaduras, no solo en el espacio por el que discurren sino en sus áreas de influencia y en los paisajes que transforman; si bien, teniendo siempre presente que dichas incidencias no son de carácter homogéneo sino que se ven marcadas por una realidad diversa, donde la relativa complejidad de la orografía y topográfica, así como las diversidades climáticas inciden, de manera directa e indirecta, no solo en la realidad paisajística sino en la interpretación y valoración subjetiva que se hace de estos paisajes, gene- 
rando nuevos análisis de la parte social de los riesgos antrópicos, a través de nuevas expresiones como resistencia y resiliencia.

Es por esto por lo que, debemos conocer e interpretar la realidad que acontece a una "región riesgo" como es la de la Comarca del Morrazo; pues el análisis territorial de la peligrosidad (natural y antrópica) y sus efectos en las sociedades humanas muestra que es posible delimitar unidades espaciales que comparten una afección similar de algún episodio de rango extraordinario (con origen natural, antrópico o de carácter tecnológico). Igualmente, el riesgo latente en un territorio se convierte en un elemento de significación geográfica importantes en el análisis de dicho medio. Así pues, riesgo llega a adquirir significación cultural y determina -condicionaactuaciones de los seres humanos sobre el territorio orientadas a reducir o minimizar sus efectos (Sotelo Pérez, M. y Sotelo Pérez, I., 2017). De este modo, surge la "región-riesgo", una unidad de análisis territorial, de dimensiones variables, que alzaprima el carácter vulnerable de una población ante un episodio natural extremo, sus implicaciones en el devenir de esa sociedad, como el rasgo más sobresaliente -o uno de ellos- de un medio geográfico.

Situada entre las rías de Vigo y de Pontevedra, la península del Morrazo se consolida como un "horst" montañoso de baja altitud (con elevaciones que no superan los 600 metros de altitud), donde los valles se entrelazan con las ensenadas, y donde el agua se abre paso formando otra ría, la de Aldán, configurando así la estrecha península de Hío. Igualmente, fruto de la topografía y de un clima atlántico, en el que los niveles puvliométricos son elevados, nacen numerosos arroyos, algunos aprendices de ríos que discurren por sus laderas modelando el terreno y conformando un paisaje diverso y complejo, donde el relieve se torna abrupto, la vegetación copiosa, la fauna diversa, ..., y, donde el hombre se abre paso, adaptándose y transformando su espacio. En las imágenes adjuntas (ver Figura $\mathrm{N}^{\circ} 3$ ), se nos muestra un territorio en el que las áreas habitadas se concentran en las superficies más cercanas a la costa, donde predominan las actividades pesqueras y de servicios; $y$, a medida que nos alejamos, ascendiendo por la colina, hacia las partes medias, el hábitat se torna cada vez más disperso, con carácter residencial, y las actividades predominantes son las de la agricultura y la explotación forestal, vinculada, principalmente, a plantaciones de repoblación de colosales eucaliptos (Eucalyptus globulus), robles (Quercus Robur), castaños (Castanea sativa), pinos (Pinus pinaster)..., así como por abundantes matorrales en los que sobresalen los tojos (Ulex europaeus) y los retamales (Retama sphaerocarpa) que tiñen de color un monte desnudo y rocoso, en el que, cada vez más aparece sembrado de viviendas unifamiliares que se adueñan del espacio y se expanden hacia las vías de comunicación y hacia el mar.

Todo ello, resultado de la interacción de una compleja conjunción de elementos -geológicos, edáficos, climáticos,...- que configuran un paisaje de una enorme riqueza, a la par que fragilidad, propias de una región, como se la denominado anteriormente, de riesgo. Remarcando, igualmente, como los episodios sísmicos condicionan, en cierto modo, la peligrosidad propia que ejercen los movimientos terrestres sobre construcciones de tales dimensiones (como se puede observar en la Figura $N^{\circ} 4$, en las proximidades del puente de Rande, el rango de profundidad se encuentra entorno a los 0 y los $30 \mathrm{~km}$ y con una magnitud entre los 3,5 y los 4,5 en la escala local, incrementándose los niveles en la zona marítima y las proximidades de la ciudad de Vigo y, siendo de notable reiteración en las cercanías de la ciudad de Pontevedra, si se tiene en consideración los estudios históricos). 
Figura No 3.

El "corredor" a su paso por la Comarca del Morrazo: la ocupación territorial.

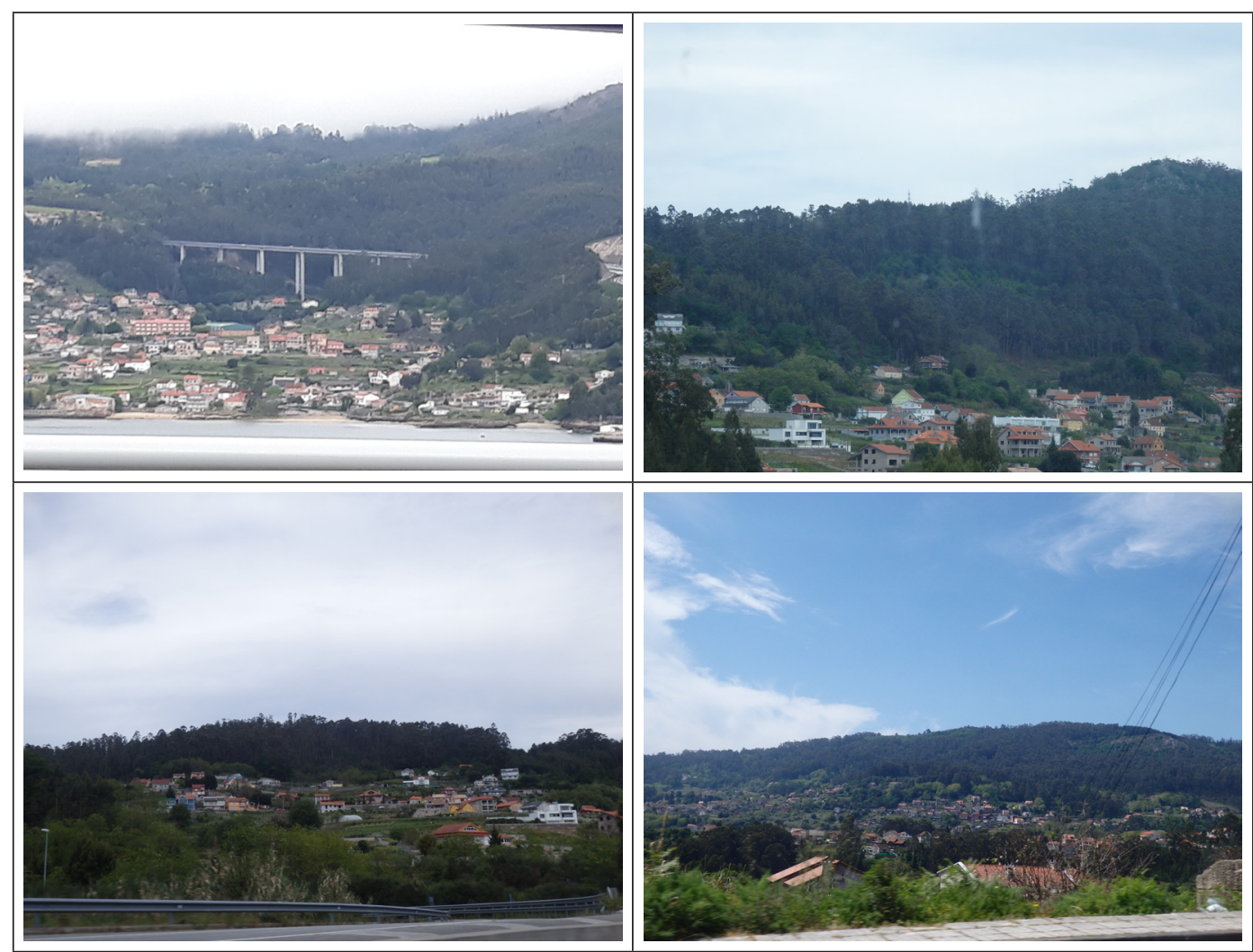

Fuente: Elaboración propia.

Por su parte, el territorio está marcado por unas condiciones climáticas diversas y complicadas, fruto de la topografía y el influjo del mar, que propician la existencia de lo que se ha denominado "micro climas" (dada su disparidad pluviométrica y térmica), y marcan una de las características más reseñables del área de estudio (ver Figura No 5). Si bien, podemos afirmar que nos encontramos ante un clima de incidencia atlántica, calificable de "suave", cuyas temperaturas medias oscilan entre los $7^{\circ} \mathrm{C}$ en invierno y los $25^{\circ} \mathrm{C}$ en verano, y, sus precipitaciones se aproximan a los $1500 \mathrm{~mm}$ anuales, e, incluso, con valores que, de manera puntual, superan los $1900 \mathrm{~mm}$ anuales, en algunas áreas (e, incluso, siendo más elevadas, en las cumbres de las sierras y los oteros). Igualmente, señalar que presenta unos elevados niveles de humedad relativa, especialmente en los meses de verano, y en ciertos periodos del año, principalmente en otoño e invierno, muestra virulentos niveles de viento, a consecuencia de las borrascas o ciclones extratropicales que crecen y se desarrollan debido básicamente a la inestabilidad baroclina, generada por el fuerte gradiente horizontal de temperatura y la fuerte cizalladura del viento, tanto vertical como horizontal -dando lugar a las denominadas "ciclogénesis explosivas". 
Figura $\mathrm{N}^{\circ} 4$.

Sismicidad en la ría de Vigo

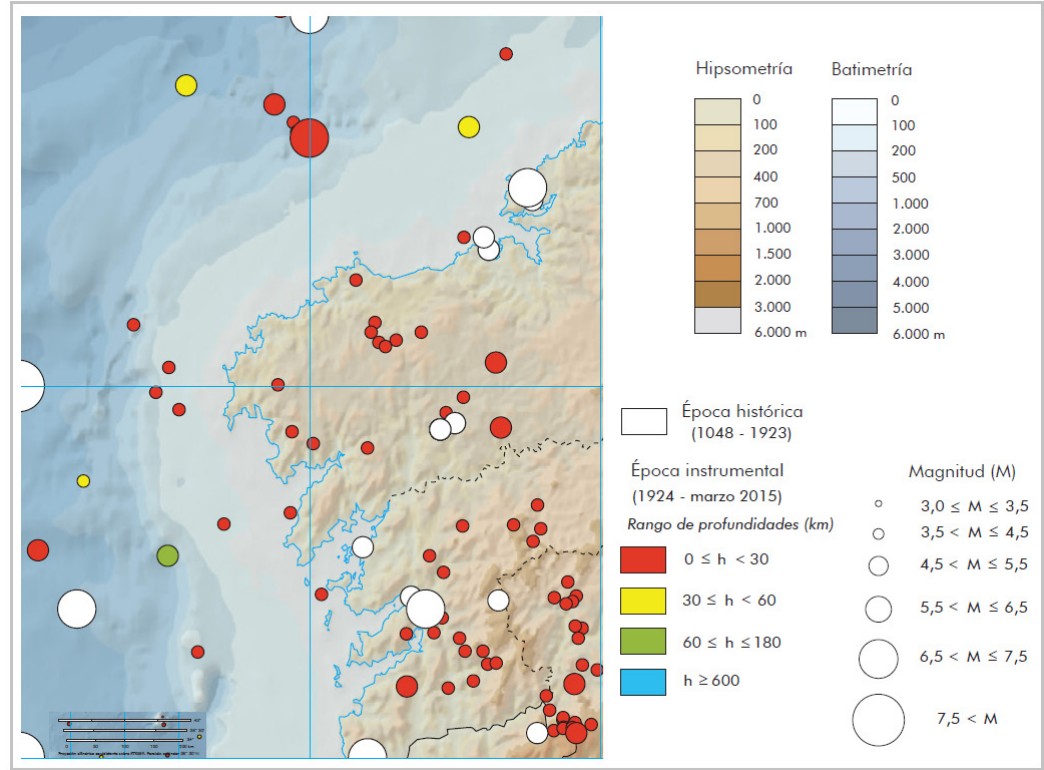

Fuente: Elaboración propia, a partir del Instituto Geográfico Nacional.

Figura No 5.

Mapa de precipitaciones y temperatura del área de estudio

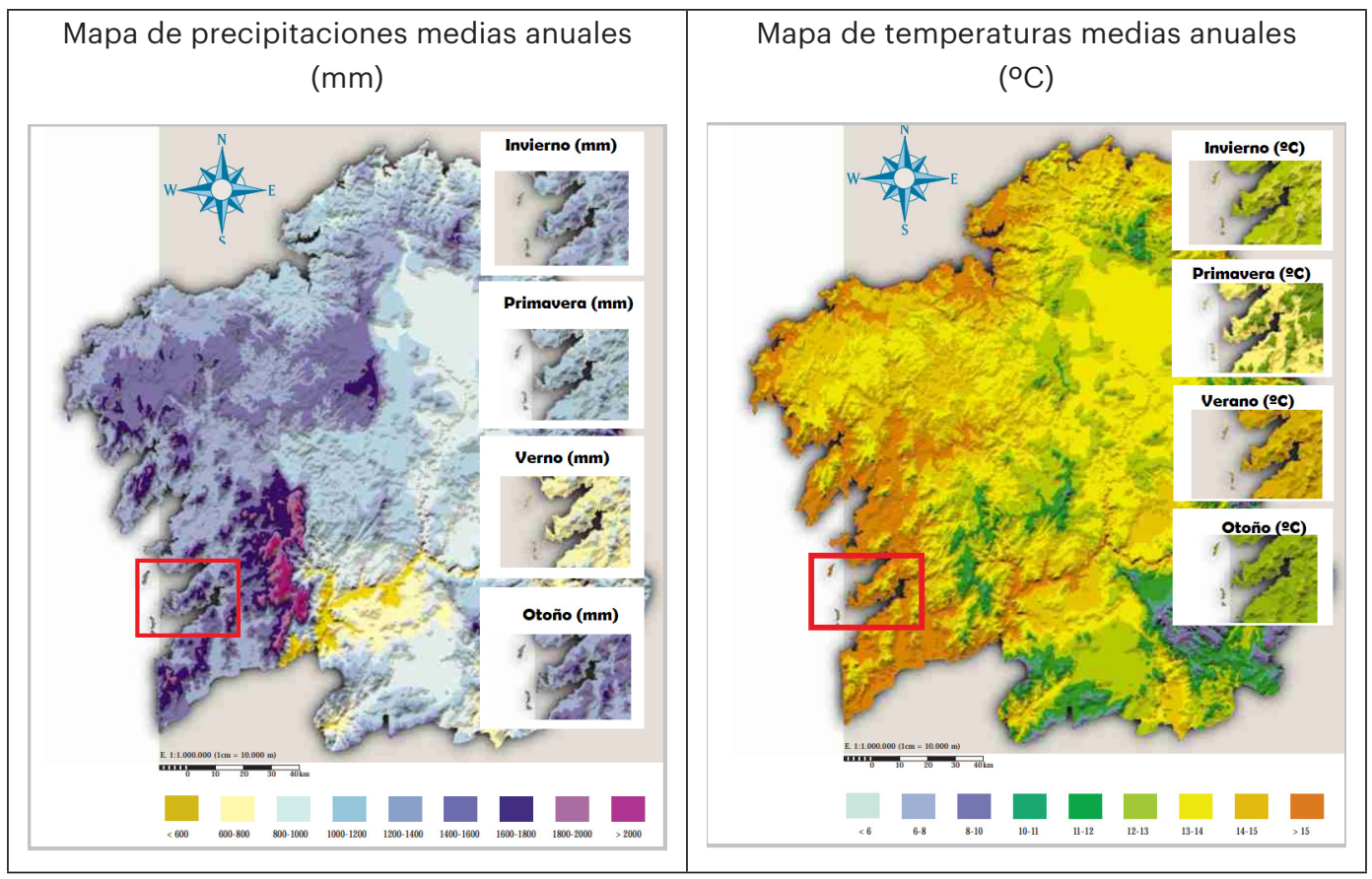

Fuente: Elaboración propia, a partir de Martínez, A. y Pérez, A., 1999. 
Por su parte, el "corredor", hoy casi convertido en autovía, recorre la península del Morrazo, atravesando diferentes unidades de relieve de litoral, conformados por reducidos acantilados, valles, y numerosas dunas y arenales (Rodeira, Tirán, do Con, la Junquera, Meira, etc.), en cuyas proximidades se asientan núcleos urbanos -si bien, unos de mayor relevancia poblacional y económica que otros, como los de Domaio, Moaña o Cangas. La vía segmenta, taja, desmembra y adapta, una realidad geográfica en la que la leve pendiente, de perfil irregular, $y$, las suaves elevaciones graníticas del macizo de la Sierra de la Magdalena, definen el propio paisaje (ver Figura $\mathrm{N}^{\circ} 6$ ). Sentando sus bases sobre rocas ígneas variscas sin cinemática, rocas del precambrico-paleozoico y depósitos cuaternarios, el "corredor" discurre por una litología de carácter granítico, donde los depósitos detríticos que cubren el fondo de valle, arrastrados por las vertientes de los arroyos o erosionados por la fuerza de los agentes atmosféricos (surgiendo así pequeñas rocas de cuarcita o pizarra), consolidan los cimientos de unas superestructuras de colosales dimensiones.

Figura № 6.

Mapa geológico del área de estudio

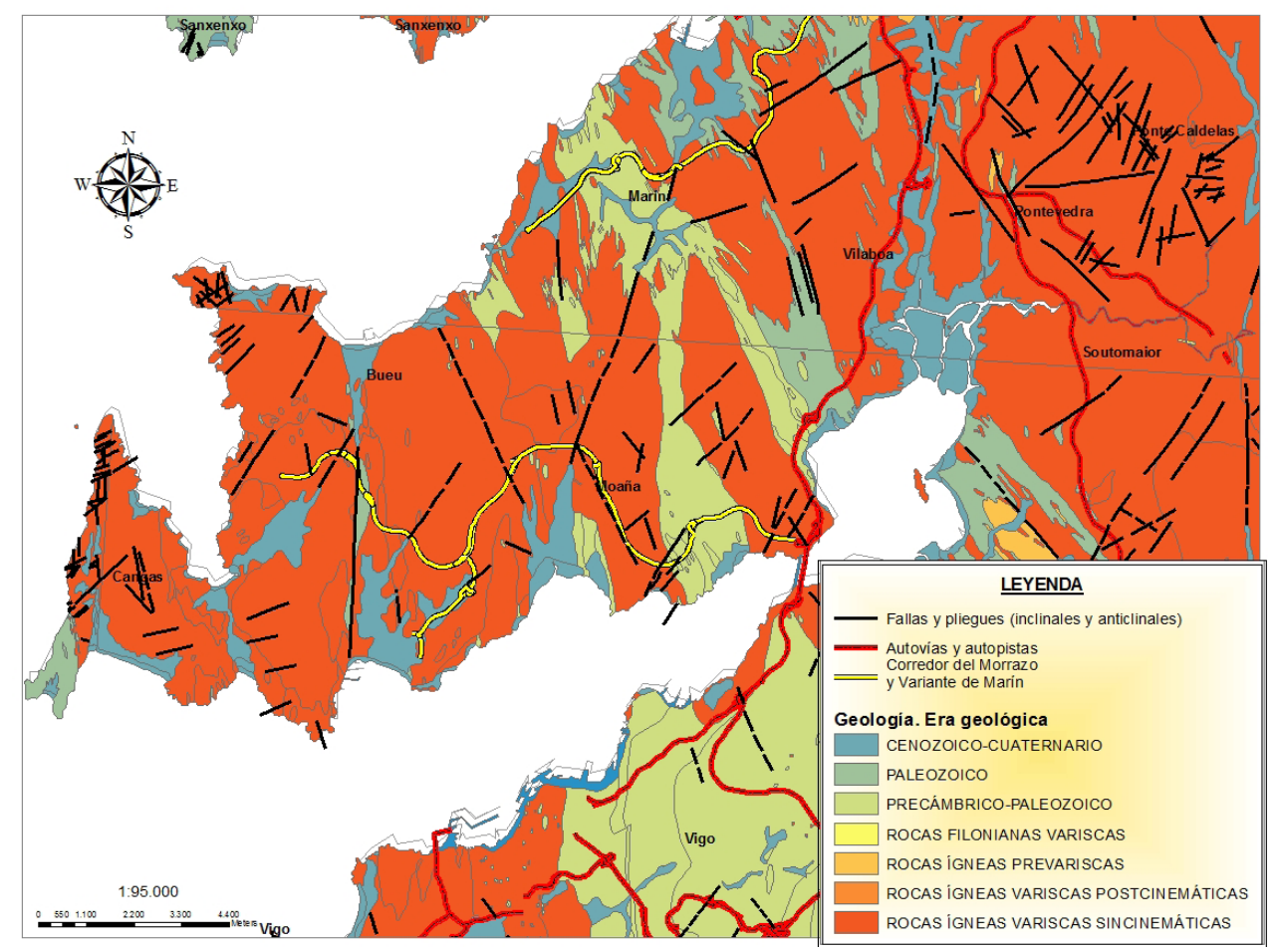

Fuente: Elaboración propia.

Con todo ello, se nos muestra como el medio natural, sobre el que se asientan las infraestructuras del "corredor del Morrazo" -que modifican, transforman y, fundamentalmente, degradan el ecosistema sobre el que discurren-, presenta una más que notable complejidad, configuran un espacio de enorme vulnerabilidad y fragilidad, donde los factores biogeográficos y bioclimáticos, condicionan los asentamientos y supeditan, no solo las capacidades, sino las propias actividades económicas que potencien un desarrollo territorial en su triple dimensión -económica, ecológica y social-. Por lo que, la ampliación del denominado "corredor", así como el área de acceso a través 
del Puente de Rande, debe ser entendido como un elemento más en el proceso de integración y mejora de la comunicación de los asentamientos poblacionales de la península del Morrazo, si bien, se deben llevar a cabo siempre, teniendo presente el cumplimiento de la legislación vigente, mediante procesos que permitan generar un sistema económico competitivo a gran escala, siempre desde la óptica de la protección y conservación de la naturaleza; eliminando y mitigando los riesgos, impactos, amenazas y daños que estos puedan ocasionar, tanto en el medio físico -a corto y medio plazo-, como en el medio humano y económico -a medio y largo plazo.

\section{Los riesgos inherentes a la construcción de las infraestructuras}

Los proyectos de grandes infraestructuras, como las que se llevan a estudio en el presente trabajo (puentes, carreteras, viaductos, etc.) generan sustanciales efectos externos sobre el medio en el que se asientan y discurren, así como en sus áreas de influencia -ya estén estas en áreas limítrofes o no-; por lo que la regulación, control y valoración de los mismos deben estar sometidos a un análisis, con el objeto principal de identificar, conocer y evaluar dichas externalidades, a través de las denominadas "evaluaciones de impacto ambiental", $y$, más especialmente en aquellos donde los territorios afectados sean tan extensos y posean unas características intrínsecas tan arduas como el que nos acontece.

Del conjunto de vías que cruzan la península, destacan la carretera PO-551 que, siguiendo la línea litoral, conecta los Concellos de Cangas, Bueu y Moaña de donde parten otras carreteras secundarias (como son la EP-1001, EP-1002, EP-1003 y EP-1104) y de caminos rurales que sirven de unión al conjunto de viviendas diseminadas por el territorio. Además, el presente "Corredor del Morrazo" (VRG-4.1) se erige como nueva vía de articulación del Morrazo con la urbe viguesa, atravesando y tajando la montaña (Figura $N^{\circ} 7$ ). Con el objeto de vertebrar la península del Morrazo y consolidar los procesos de expansión del área metropolitana de Vigo, a través de la mejora de la comunicación terrestre entre esta y los distintos concellos de la Comarca del Morrazo; en el año 2016 dan comienzo las obras de ampliación del denominado "corredor del Morrazo" (el cual fue construido entre los años 2001 y 2005,y cuyas obras estuvieron estrechamente relacionadas con la catástrofe del hundimiento del Prestige), las cuales, superando las expectativas del proyecto inicial -finalización en 2018-, aún continúan ejecutándose. Si bien, debe remarcarse que, en primera instancia, las obras de ampliación del "corredor" cuyo objeto es la vertebración, tal y como establece POLGALICIA, generando un conflicto a la hora de establecer la prioridades entre los impacto sociales y los ambientales, especialmente, si no se realiza una valoración óptima de los efectos, a corto y medio-largo plazo, así como en las vulnerabilidades de unos y otros elementos, a la hora de hacer frente a los riesgos emanados de unas obras de tales dimensiones (Figura № 8).

Según lo expuesto, los riesgos antrópicos, en definitiva, los peligros que ocasionan las actividades del hombre sobre la naturaleza, afectan al conjunto de la sociedad en su doble dimensión, individual y colectiva. En la primera -su dimensión Individual-, repercuten en las actuaciones en el que el individuo no puede disfrutar y utilizar libremente el medio en el que se desarrolla, sin la irrupción de cualquier otro sujeto particular, empresa u organismo público de cualquier clase, encontrándose sometido en sus decisiones, en cuanto a la utilización de su entorno, a algo más que a su propio poder decisorio de autodeterminación. Poder que puede ser ejercitado gracias a 
Figura $N^{0} 7$.

Sistemas de Infraestructuras viarias en el Morrazo

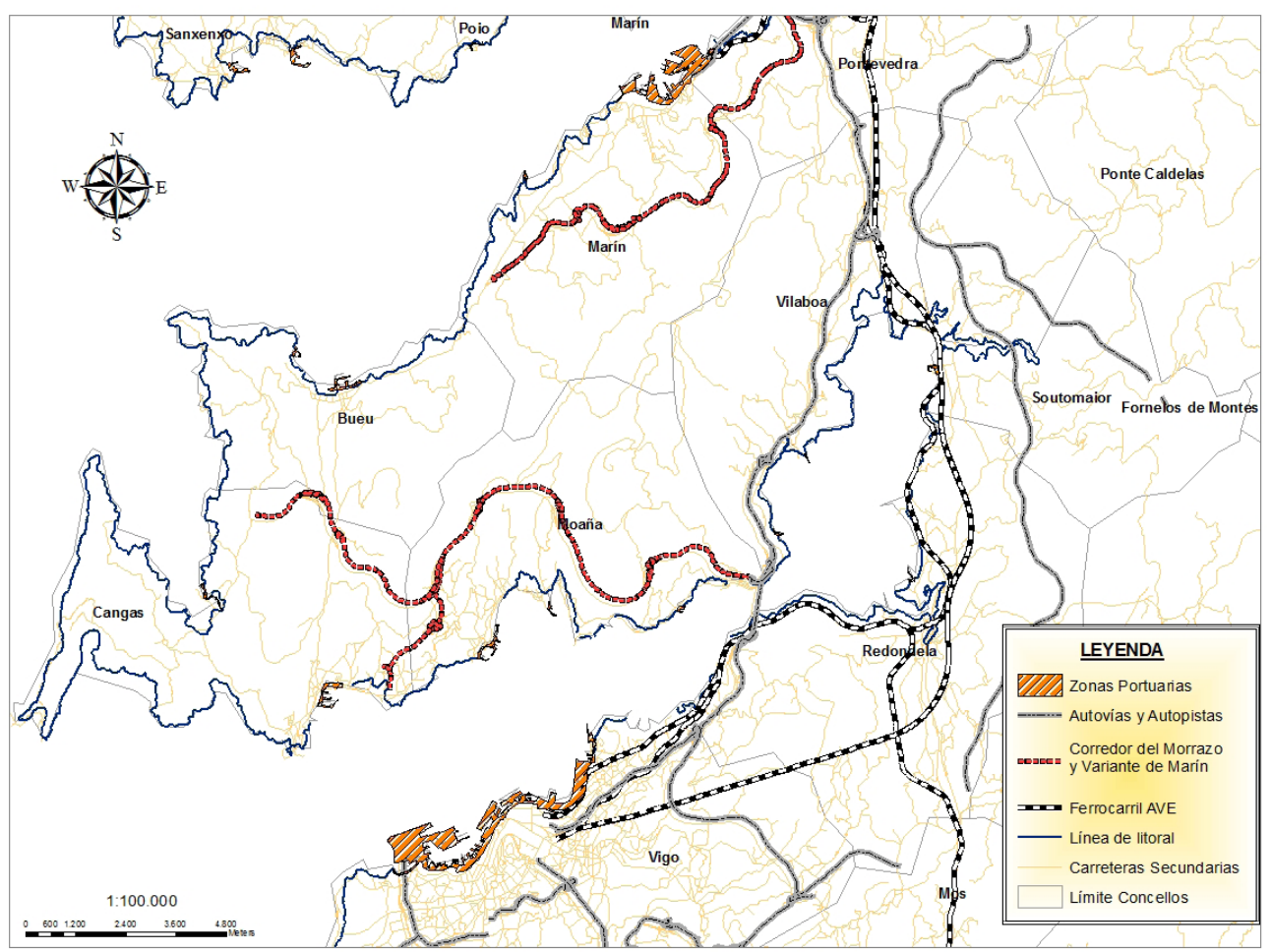

Fuente: Elaboración propia.

un ordenamiento legislativo que le protege y le ampare frente a injerencias ajenas a su ser particular y que se ejerza con respeto y cuidado sobre los bienes naturales (producto de la educación solidaria que las instituciones estatales garanticen y exijan a cualquier ciudadano). En cuanto a la segunda -su dimensión colectiva-, en el sentido de no poder disfrutar participativamente de las decisiones que cobran importancia en el seno de su colectividad social, en aquellas decisiones que tienen incidencia directa e indirecta sobre el medioambiente y que, de una forma u otra, cada ciudadano se siente participe real, de la formación de la voluntad pública, provocando que los habitantes de los distintos territorios se sientan de forma real o ficticia desplazados en la toma de decisiones que influyen en su medio físico y natural (siguiendo los trabajos de Sotelo Navalpotro, J.A. et alii, 2016, y Tolón Becerra, A., Lastra, X. y Sotelo Navalpotro, J.A., 2012). En definitiva, con la participación de los ciudadanos en la toma de decisiones públicas, como son aquellas que afectan al medio ambiente y por lo tanto a sus derechos, y al libre disfrute del medio y desarrollo de su personalidad, se consigue que el ciudadano se realice como persona, sin responder a intereses de corporaciones, empresas privadas, que lo único que intentan es convencer de que se tiene en cuenta al ciudadano para lograr un desarrollo que le beneficia directamente, y no al revés). 
Figura No 8.

Localización territorial del “Corredor del Morrazo"

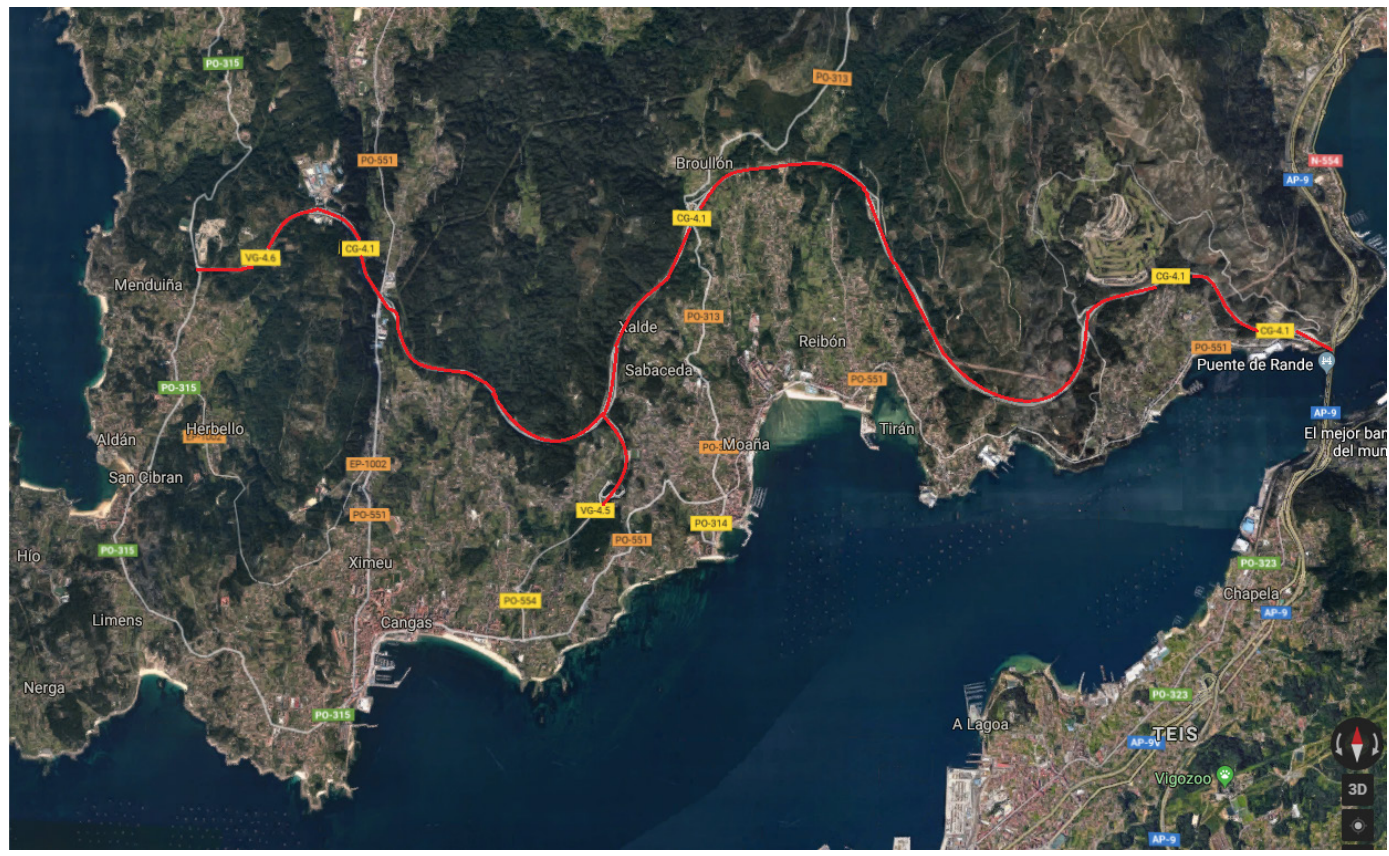

Fuente: Elaboración propia, a partir de "googlemaps"

Por lo que, al aproximarnos a la realidad que acontece al denominado "corredor" -ya más próximo a autovía, consecuencia de sus obras de ampliación-, éste tiene por objeto de "romper" con el aislamiento a la península del Morrazo (donde encontramos los concellos de Marín, Moaña, Bueu, Cangas, y Vilaboa), y favorecer la dualidad espacio vs. Tiempo -disminuyendo la duración de los trayectos, y mejorando la movilidad de la población, a través de la interconexión de los diferentes territorios-, y, por ende, a mejorar la realidad poblacional para la cual, en teoría, se construye y se amplia la carretera (ver Figura No 9). En el convencimiento de comprender, que el saber y la interpretación que se puede hacer sobre la realidad que nos rodea, no puede basarse en afirmaciones ni en verdades absolutas, y en el entusiasmo de ser capaz de cuestionar las interpretaciones y convencionalismos ya existentes, corresponde aquí, en la investigación que ve la luz en estas líneas, aportar nuevas formas, creando nuevos esquemas de interpretación de la realidad, el entorno, nuestro medio más cercano. Ni el más verdadero, ni por supuesto el único posible, simplemente el que creemos que es el más válido y aceptable para poder superar las interpretaciones, regulaciones y usos, ya establecidos en nuestra sociedad; en definitiva destinado a ser estudiado, investigado y sirviendo las aportaciones aquí presentes. Junto con los riesgos naturales, per se, la actividad humana como tal, aislada de las decisiones macroeconómicas, no es la que produce los riesgos, ya que es la actividad económica la principal cusa del impacto natural, acorde con las necesidades de crecimiento y consumo de aquellos que ocupan y explotan el medio. Son los impactos generados por las políticas económicas, debido a la potencialidad dañosa que genera las decisiones y puesta en práctica de las mismas, las fuente primaria de situaciones productoras de daños (Sotelo Pérez, M. y Sotelo Pérez, I., 2017). Políticas causantes de forma directa de la generación de lo que denominamos como riesgos; es decir, la actividad human, no 
es la principal generadora de los impactos, peligros o riesgos, entendida esta como la práctica diaria que cualquier sociedad desarrollada realiza dentro y fuera de los asentamientos urbanos o rurales, sino que nos encontramos con que son aquellas actividades económicas, predeterminadas por el modelo económico, y sustentadas por regulaciones jurídicas dictaminadas por determinadas políticas también económicas, las que coadyuvan al establecimiento de infraestructuras y acciones que se convierten en fuente directas de daños y peligros indeterminados (en muchas ocasiones), sobre el territorio en el que se instalan.

\section{Figura No 9 .}

Mapa de ampliación del "Corredor"

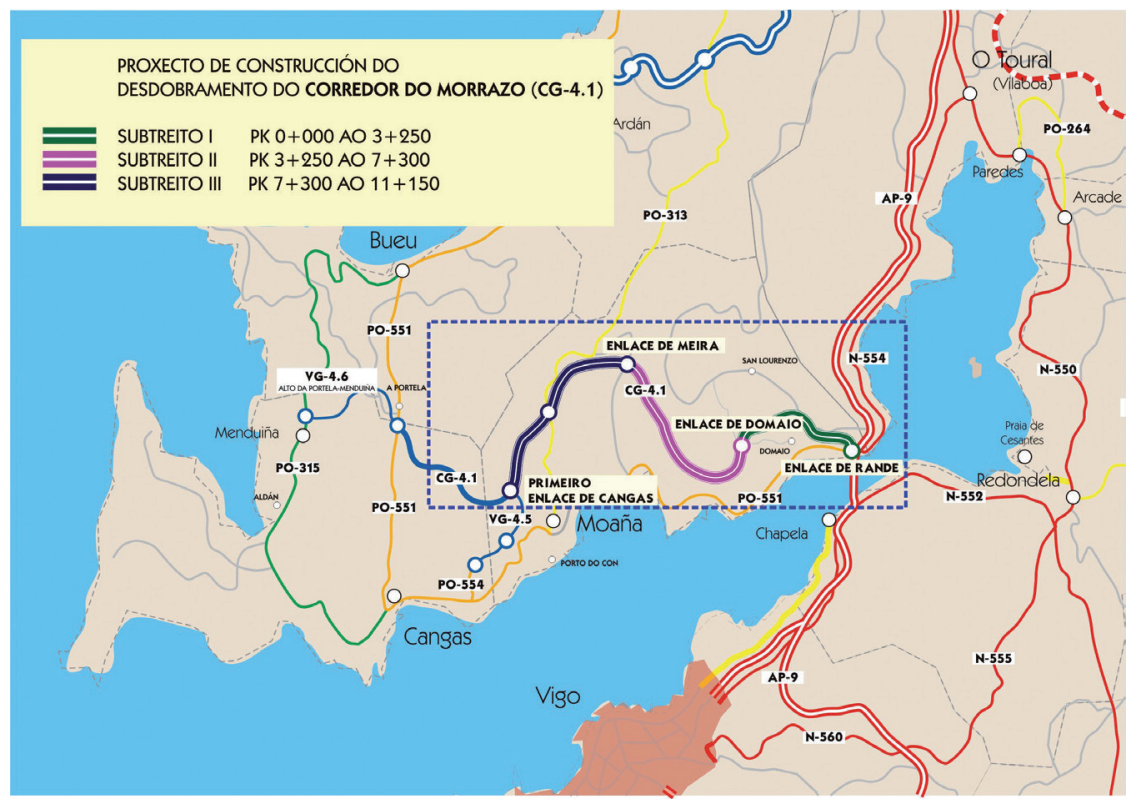

Fuente: Elaboración propia, a partir de Atlantico.net, 2017.

Así pues, con a través de la información recabada, desde el año 2009 hasta la actualidad, se hace constar una realidad poco halagüeña como es la decisión de no realizar una "evaluación de impacto ambiental" en la ampliación de la autopista del Atlántico a su paso por el Puente de Rande, cuestión que cobra mayor notoriedad en el año 2012 -tal y como se expone en el "marco teórico"-, cuando en se deja constancia -amén de remarcar el ingente número de accidentes que habían tenido lugar en esta vía desde su construcción-, de la intencionalidad de desdoblar el "corredor" en cuatro carriles para convertirlo en autovía, de manera poco transparente y sin dejar constancia de la intencionalidad salvo los respectivos comunicados a los concellos de Cangas y Moaña (puesto que la idea inicial es la de convertir el vial en autovía solo en esta parte del territorio para reducir costes), por ser los afectados por dichas obras de ampliación, en los que se remite los planos del nuevo proyecto para consultar la existencia o no de impactos medioambientales importantes y, de este modo, no tener que realizar una nueva "evaluación de impacto ambiental". De este modo, se procedería al desdoblamiento de carriles, a derecha e izquierda de los existentes, desde el Puente de Rande (donde, además se llevan acabo obras de ampliación) hasta el desvío hacia el concello de Bueu, atravesando así, los concellos de Cangas y Moaña. Por su parte, la empresa ICEACSA desarrolla un estudio técnico con el objeto de conocer, pronosticar, prevenir 
y, subsanar los impactos, daños o amenazas emanados de la ampliación del "corredor", generando así un estudio de impacto ambiental, estableciéndose así que la ejecución del proyecto debía realizarse en consonancia con el buen uso, racional y protector de las obras de ampliación; a través del cual mostrar que existe una relación y correlación entre la protección ambiental y la interacción entre los habitantes y su medio (acorde con la capacidad de acogida y la capacidad de carga de este). Por último, se establece un Programa de Vigilancia Ambiental, con el objeto de vigilar y controlar los impactos y presiones que puedan emanar de dicha ampliación, aplicando medidas de protección, conservación y regeneración, tal y como se establece en la "evaluación de impacto ambiental", si bien, como se pone de manifiesto, la realidad que acontece a las obras de ampliación supera cualquier estudio previo y la degradación, destrucción o impacto que se genera -tanto durante como después de la realización de las obras- supone un riesgo real y potencial para un territorio, como se ha expuesto con anterioridad, sumamente frágil y vulnerable.

\section{Estudio de casos en un espacio en transformación}

Tras lo anteriormente expuesto, la ampliación del denominado "corredor del Morrazo", con el objeto de convertirlo, en los momentos actuales, en autovía, ha supuesto una enorme presión y un más que considerable impacto en el territorio sobre el que se asienta y discurre, dando lugar a importantes riesgos de carácter antrópico, en el territorio gallego.

Indiscutiblemente, la construcción de un trazado vial supone siempre un impacto, tanto real como potencial, del medio físico y del medio humano y económico, suponiendo una variación del paisaje, modificando la morfología del terreno, generando una gran presión sobre el suelo por el que discurre, e, impactando sobre el aire, los recursos hídricos, la geología e hidrología, los suelos, la flora y la fauna,..., lo que, como se ha mostrado anteriormente, surge una imperiosa necesidad por incluir los elementos del medio físico como componentes esenciales en el ámbito de la planificación y proyección de unas obras de infraestructura, en general y, más aún de unas edificaciones de tales dimensiones, en particular; pues los impactos y presiones generados pueden incurrir en riesgos imprevisibles que produzcan daños irreversibles para los sistemas biológicos sobre los que se asientan -tal y como se ha mostrado en el "marco teórico"-, así como para sus áreas de influencia. En el caso concreto que nos acontece, las obras de ampliación del "corredor del Morrazo" han supuesto un proceso de destrucción titánica, afectando de manera más que notable a la alteración del paisaje; ejemplo de ello lo entramos en las voladuras producidas para desmantelar el marco geológico estructural, provocando la alteración y deformidad del paisaje, visible desde cualquier parte de la costa, especialmente, desde la propia ciudad viguesa (Figura No 10).

La Sierra, tal y como se analizó anteriormente -conformada por rocas granitoides y por paraneises-, se ha visto afectada por la voladura de sus márgenes y el fallado de sus paredes; lo que genera un impacto en el drenaje, tras provocar cambios en la hidrología natural, que propicia riesgos de acumulación e inundación de áreas concretas, cambios en los cauces y en los caudales de los arroyos; alteraciones en las "caídas de aguas" que favorecen los desagües naturales de los cuantiosos niveles de precipitación de agua propios del clima atlántico; desprendimientos del roquedo -que superan las medidas de contención fijadas con mallas metálicas-; deslizamientos de laderas que ocasionan numerables colisiones y problemas de circulación; problemas de inun- 
Figura No 10.

Destruyendo montañas, transformando paisajes.
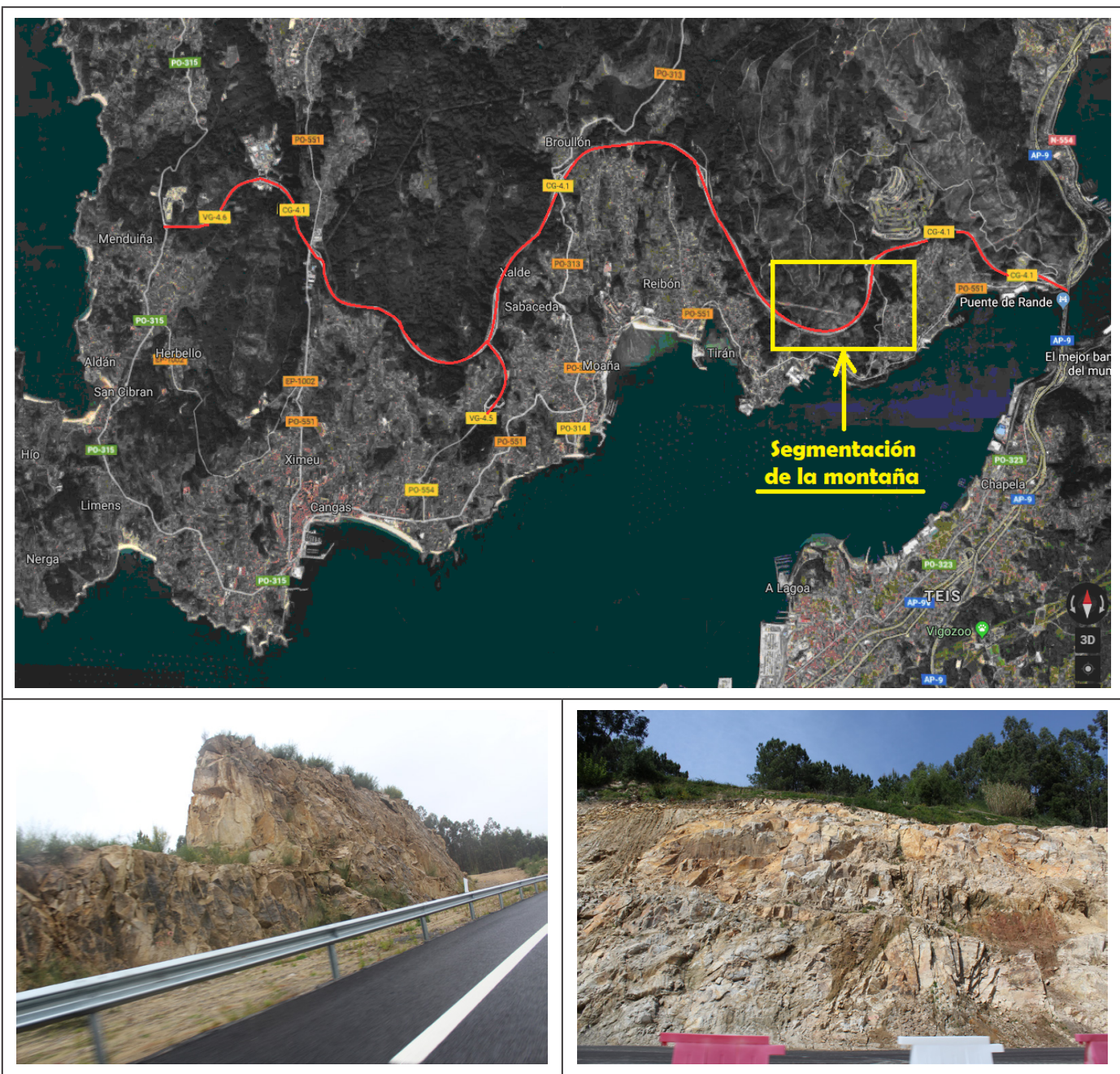

Tal y como se nos muestra en las imágenes, uno de los mayores impactos producidos por la ampliación del "corredor" lo encontramos en el proceso de destrucción de la montaña. Lejos de adaptar la red viaria al medio físico sobre el que se asienta, la construcción del "corredor" transformó inicialmente el entorno $y$, con su ampliación, los impactos sobre este se han incrementado, más que sustancialmente, desde el comienzo de las obras. Todo ello se concreta, no solo en un impacto visual, perceptible desde el espacio -donde se puede observar, con toda nitidez, todos los tajos realizados en el macizo-, donde la verticalidad de la montaña y la propia orografía se ven transformada por la horizontalidad de la carretera; sino en la propia vegetación de robles, castaños, eucaliptos o matorrales, entre otros, que se han destruido para proceder a la voladura de las paredes rocosas; en una fauna afectada por la destrucción de su entorno -lo que origina la perdida de muchos animales que no se adaptan a las nuevas condiciones de su ambiente-; en una población afectada por nuevas formas de contaminación de su medio -contaminación lumínica, acústica, vibraciones, etc.-, donde su base económica tradicional -minifundista o de explotación forestal- se ven damnificados por una construcción que, junto con las condiciones climáticas, trae consigo procesos de erosión, deslizamientos de ladera, presión sobre el territorio,...

Fuente: Elaboración propia. 
Figura No 11.

El "sembrado" de viaductos y su impacto en el ecosistema.
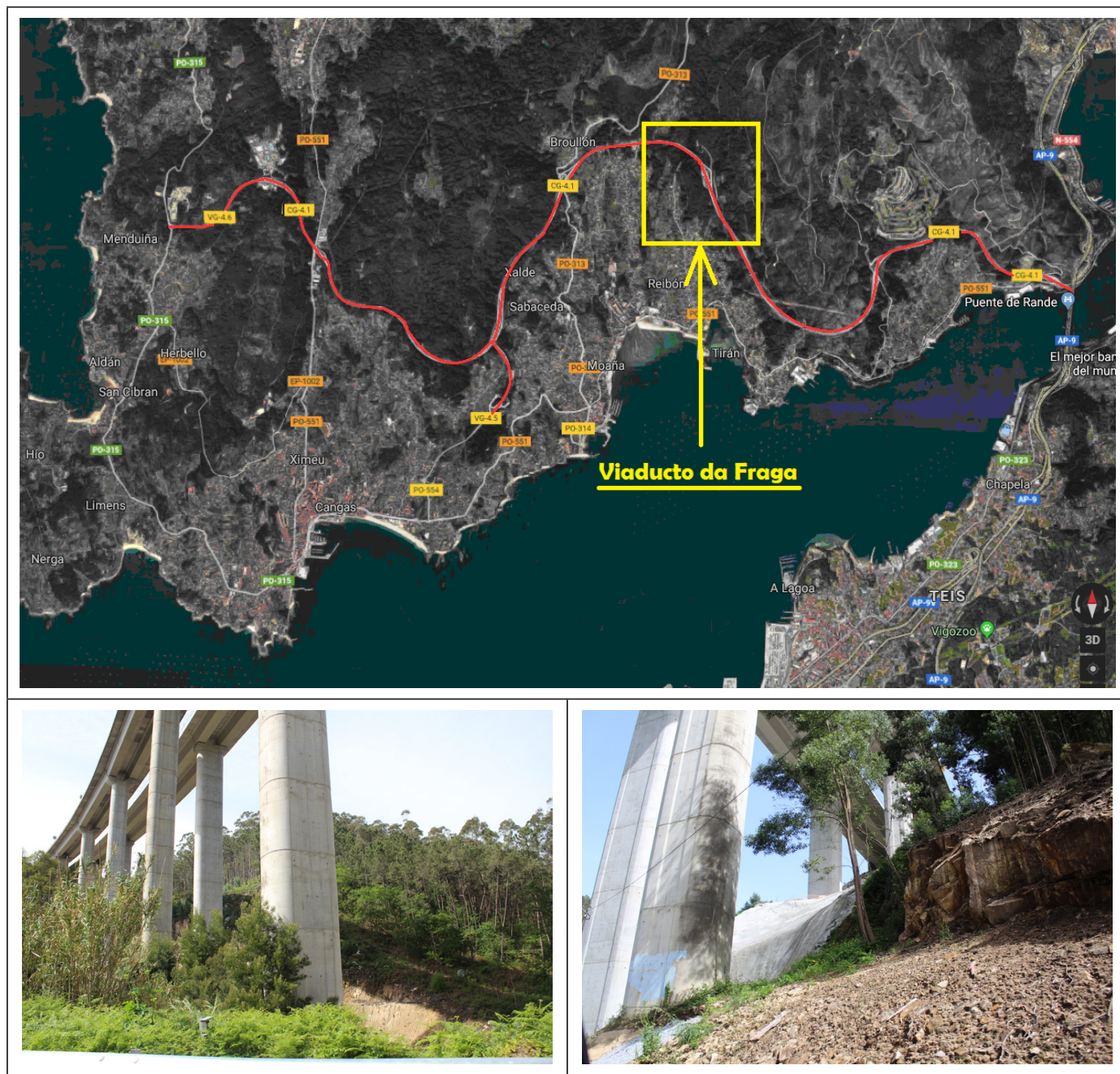

Haciendo frente a la complejidad del relieve, donde los valles marcan el devenir de los cursos del agua, y la vegetación de robles, castaños, eucaliptos, etc. crece en todo su esplendor por los picos de Ourelo, O Facho, O Carballiño..., sirviendo de hábitat a una fauna autóctona de notable riqueza -especialmente de jablíes (Sus scrofa), reptiles, aves como los zampullines (Tachybaptus ruficollis), colimbos (Gavia Immer), fulmar (Fulmarus glaciales)- y, donde las pérdidas son ya palpables, pues algunas especies se encuentran en peligro, dada su vulnerabilidad, en esta región -ejemplo de ello lo encontramos en el erizo europeo (erinaceus europaeus)-; crecen los pilares de los viaductos que permiten salvar los cauces de los ríos Bouzas, da Fraga, Moura,..., bañando de asfalto las laderas de las montañas, destruyendo las cubiertas vegetales y dejando al descubierto la roca madre, y propiciando la especulación urbanística en las proximidades de los viaductos, propiciando un aumento progresivo y desmedido de los riesgos sobre el medio y sobre la población, amén del enorme impacto visual que ocasiona.

Fuente: Elaboración propia. 
daciones que afectan a los núcleos de población, en general y a las vivencias unifamiliares dispersas a lo largo y ancho de la ladera y los valles; incremento de la contaminación acústica y por vibración; degradación y destrucción de la vegetación; devastación y demolición de yacimientos prehistóricos, etc. Así como, durante el proceso de detonación llevados a cabo durante el periodo de duración de las obras, el incremento progresivo de los riesgos producidos por los gases emitidos con las voladuras y sus posteriores precitaciones sobre el área del "corredor" así como sus áreas de influencia, consecuencia de las rachas de viento señaladas anteriormente; los riesgos por incendio, la contaminación acústica y lumínica que afecta tanto a la población residente y como a la fauna por la destrucción de su hábitat, entre otras cuestiones que se nos muestran a lo largo y ancho de dicho territorio.

Según transitamos por la vía del "corredor", la cual no ha sido cerrada al tráfico durante el proceso de construcción y modelación de la misma, se nos muestra una clara segmentación entre un espacio natural vital y dinámico, en el que aún es palpable una cubierta vegetal pletórica y abundante y una vida silvestre en plena ebullición, donde el mar y el cielo se hacen uno en el horizonte; $y$, un trazado viario que se abre paso en medio de la naturaleza, solventando las adversidades orográficas y sembrando los valles y laderas de bloques de hormigón en forma de vigas y pilares que surcan sus caminos donde nacen ríos, arroyos y "regatos" que serpentean en su corto camino hacia el mar (Figura $N^{\circ} 11$ ).

Todo ello, no solo ha modificado el medio natural de la península del Morrazo sino que ha transformado la realidad económica de sus habitantes (tradicionalmente orientada ala pesca y la agricultura y ganadería de supervivencia, y, donde la actividad industrial, tardía y siempre relacionada con el mar), donde los nuevos modelos de desarrollo, marcados por el actual sistema de mercado, propician la expansión de viviendas unifamiliares - de primera y segunda residencia-, con las que hacer frente a un "efecto llamada" de población que reside en la metrópoli de Vigo y desea mejorar su "calidad de vida", viviendo en espacios menos urbanizados y aún sin esquilmar o, apenas degradados; o, los movimientos pendulares propios de aquellos que residen en Moaña o Cangas y, a colación de estas nuevas redes de vertebración, salen de sus tradicionales aldeas -ya inexistentes- para ir a trabajar a diario a la ciudad viguesa y regresan a la noche a sus casa, donde los minifundios, la pesca o la ganadería ya no forman parte de su actividad (Figura No 12). Lo que no solo transforma la realidad económica, sino social y cultural, donde las tradiciones se han perdido o apenas se practicas, el ocio de ferias y verbenas donde la gente se relacionaba, conocía, y socializaba, se ven sustituidos por el individualismo del vehículo privado, y en el mar, junto a las grandes bateas apenas salen barcas de pesca que son reemplazadas por barcos de recreo. Es por esto por lo que, para hacer frente a estas ampliaciones y permitir el acceso de las viviendas dispersas por el territorio, se torna imprescindible alargar y ampliar los puentes de acceso que permitan superar las complejidades topográficas y una naturaleza exuberante. Esto supone un aumento de la presión en el territorio, especialmente vinculante a la polución del aire y del agua, así como de la contaminación acústica (Figura № 13).

De igual modo, el proyecto de desdoble del "corredor del Morrazo" conlleva pareja la realización de obras de mejora y ampliación de su eje principal de entrada de vehículos, el Puente de Rande; el cual atraviesa la Ría de Vigo, dando unión y conexión entre la gran urbe y la propia península del Morrazo, así como núcleo de interconexión con la capital de provincia, la ciudad de Pontevedra. 
Figura No 12.

Superando obstáculos: la ampliación de los puentes.
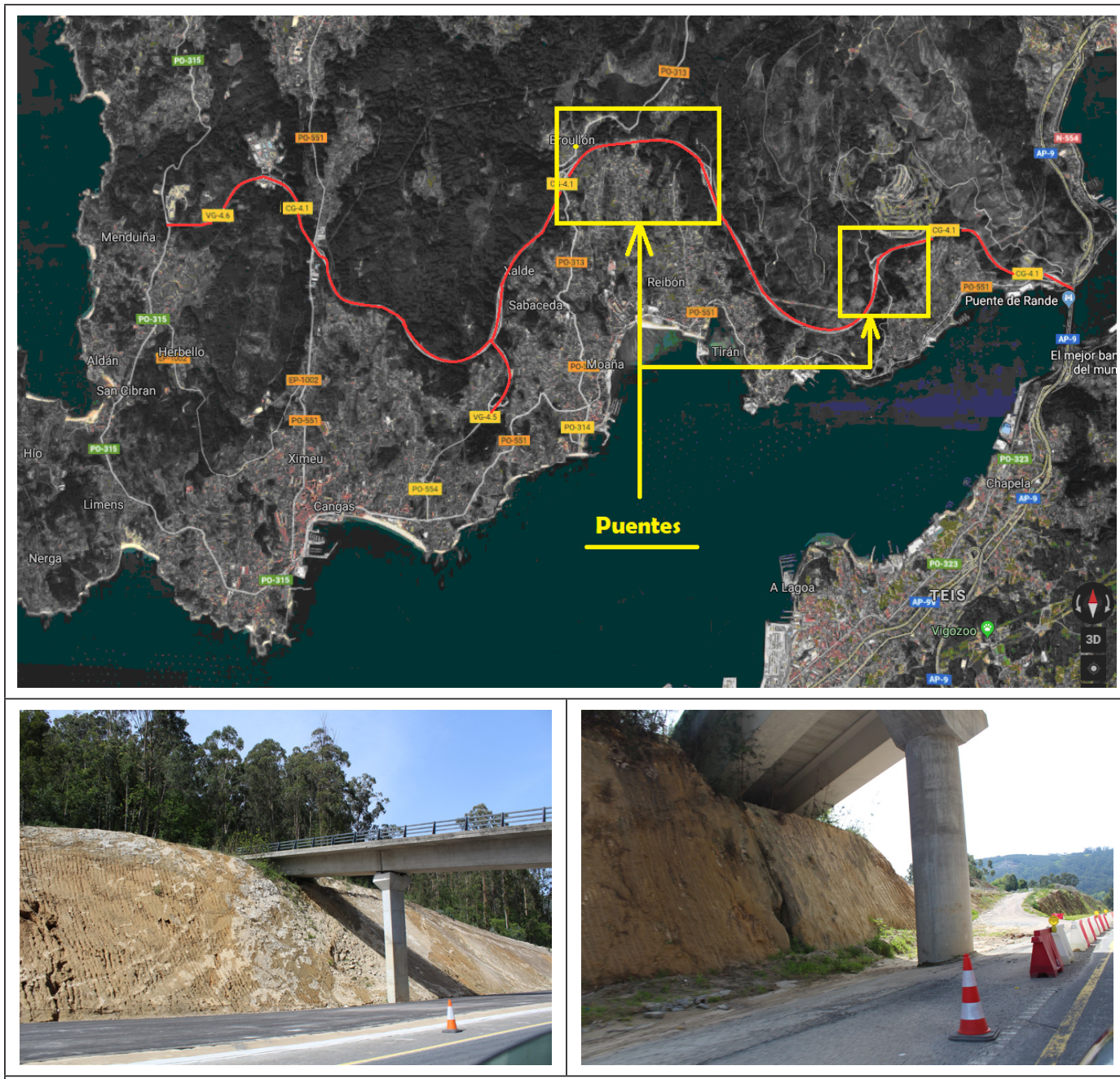

Los riesgos inherentes de la propia construcción de un puente se intensifican a la hora de analizar un territorio donde, en algunas de las zonas por las que pasa la vía y sus puentes de acceso, están preservados mediante alguna figura de protección, tal es el caso que nos acontece, donde encontramos una Zona Especial de Aves (ZEPA). Todo ello, no solo intensifica los riesgos emanados de la construcción de una carretera de tales dimensiones y de sus puentes de acceso desde cualquier parte del territorio -pues estos puentes, finalmente, acabarán tajando las montañas para construir, ampliar o mejorar las vías a las que unen-, sino que suponen nuevos riesgos para la fauna, flora, población, etc. de su entorno, amén de una importante presión sobre el suelo. Estos puentes, lejos de mimetizarse con su medio suponen un enorme contraste, ya sea porque rompen con la línea visual propia de un terreno discontinuo e irregular o porque los materiales empleados en su construcción no guardan relación alguna con los existentes en el propio territorio.

Fuente: Elaboración propia. 
Figura № 13.

Desdoblando vías, duplicando impactos.
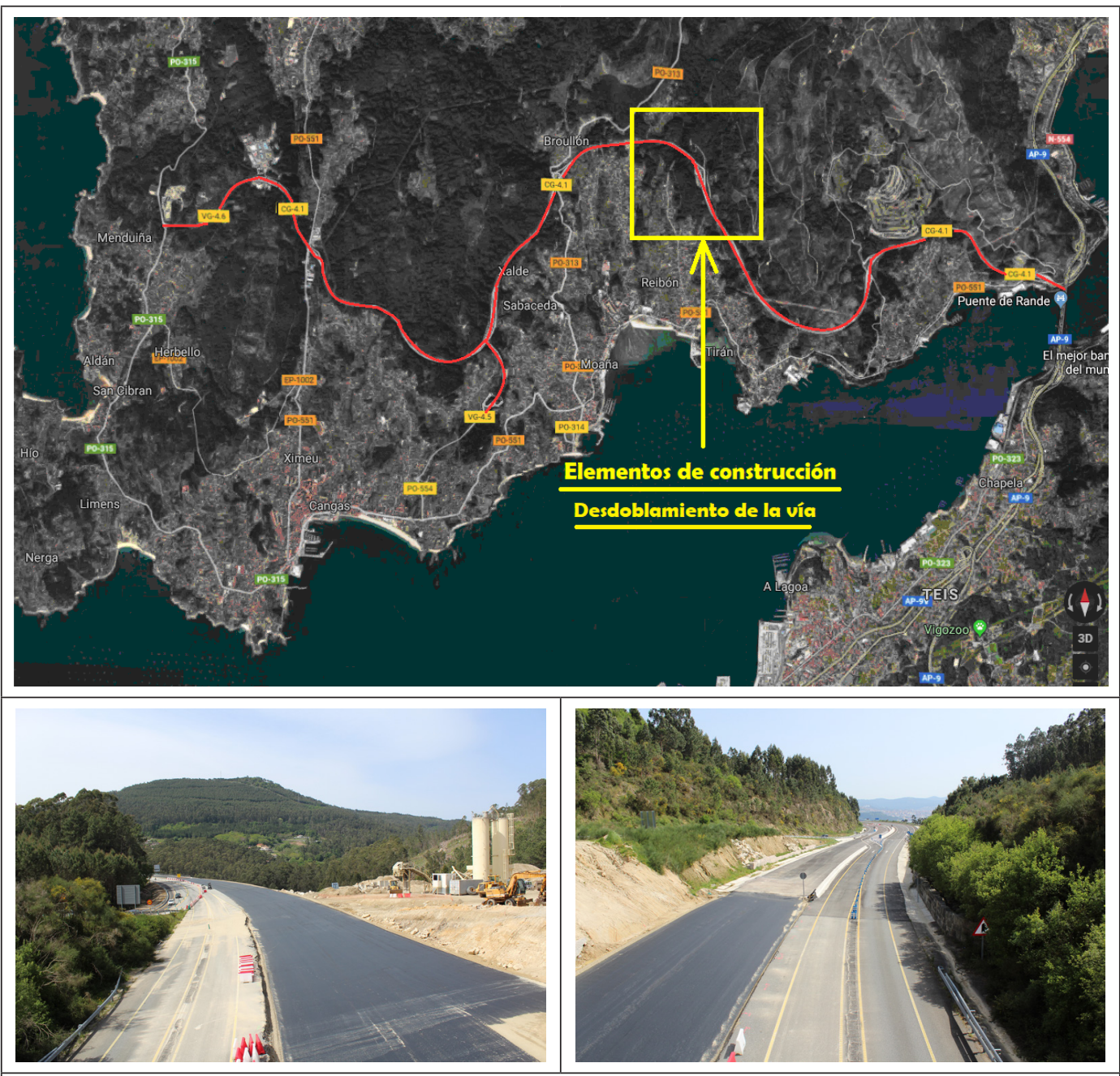

Amén de los riesgos emanados de los propios procesos de ejecución de las obras, que han supuesto "regar" de maquinaria - plantas mezcladoras, bombas de agua, rodillos, bulldozers, motoniveladoras, excavadoras, etc.-, que generan un enorme impacto visual que favorece la merma de los valores naturales, paisajísticos, culturales, etc.; importantes impactos sobre el medio físico -aire, tierra, agua, vegetación, fauna,...-, especialmente, por el incremento de la presión sobre el mismo; aumenta los procesos especulativos, de construcción masiva y descontrolada; e, impone un nuevo modelo que incrementa, de manera exponencial, los riesgos antrópicos. Éstos se incrementan y se hacen patentes ante a imperiosa necesidad de hacer frente a los numerosos accidentes viales, por la falta de dotación de infraestructuras que permitan a los conductores de disponer de todos los sentidos puestos en la carretera. Actualmente, nos encontramos en un territorio marcado por las intensas lluvias y unas persistentes e intensas nieblas que dificultan la visibilidad, por lo que, para mitigar o reducir los riesgos como, por ejemplo, los acaecidos por los accidentes, se debería incorporar alumbrado, señales luminosas, etc. para hacer frente a las condiciones adversas propias del clima y de la oscuridad, tanto nocturna como diurna.

Fuente: Elaboración propia. 
Figura No 14.

La ampliación del puente de Rande como eje potenciador de un territorio de riesgo
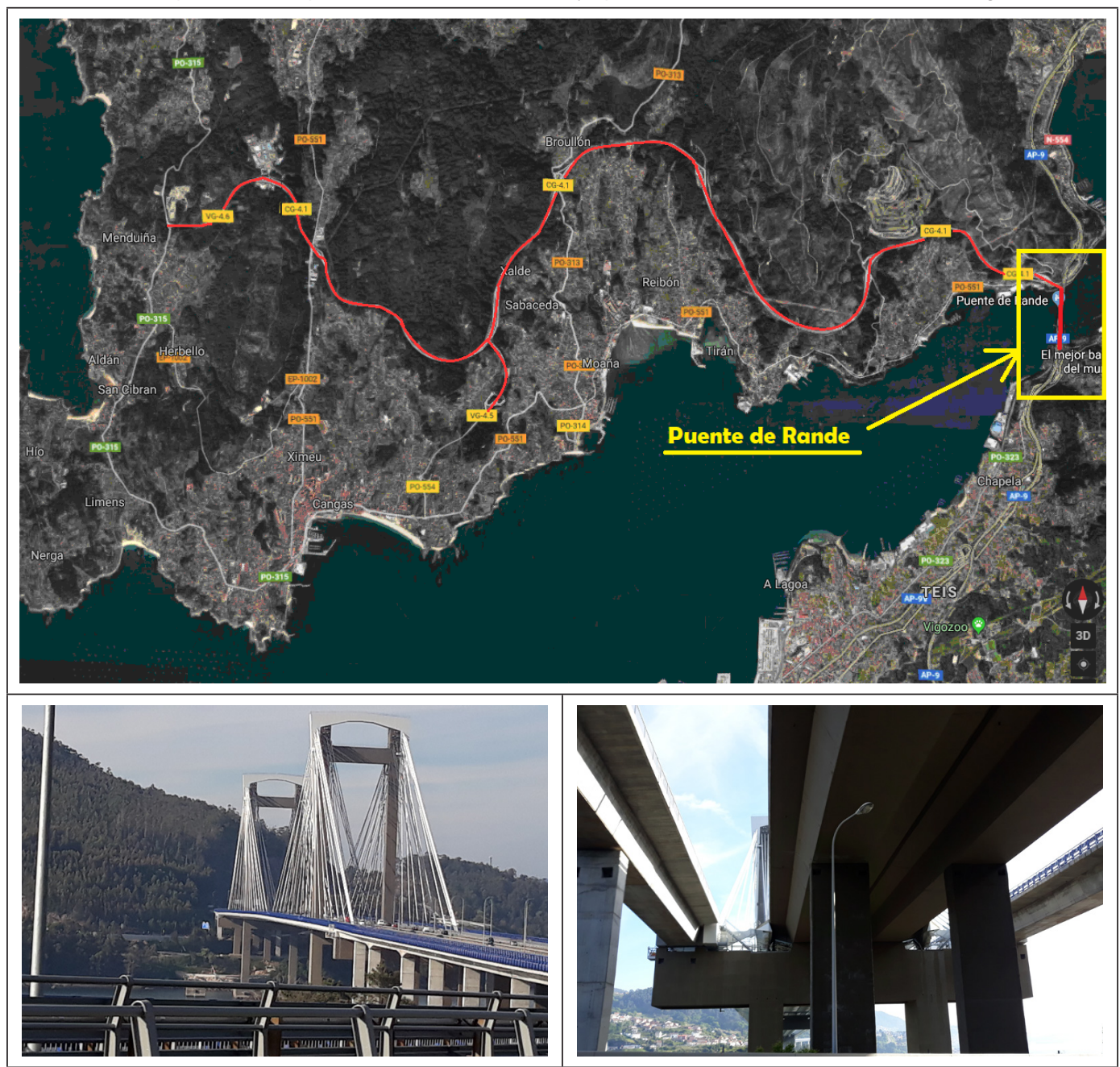

Sin lugar a dudas, la ejecución de la colosal obra de ingeniería del puente de Rande, supuso uno de los mayores generadores de riesgo en nuestra área de estudio, y, con su puesta en funcionamiento y, en los momentos presente, con la ampliación del mismo, tanto los niveles de impacto sobre el medio y la presión sobre su entorno, han supuesto y suponen una clara amenaza ambiental. Indiscutiblemente, el impacto visual proyecta una imagen desgarradora y denigrante de un espacio natural de colosal valía; ejemplo de una naturaleza viva. Sus pilares se erigen desde las profundidades de la ría de Vigo, y se muestran como gigantes monumentales que rasgan los mares alzando su vista hacia el cielo, rompiendo con la dinámica visual del entrante de la ría hacia la ensenada de San Simón de donde fluyen las aguas uniendo el cielo, la tierra y el océano Atlántico. Por su parte, el tráfico continuo, hoy incrementando tras la ampliación del puente, destruye el silencio y lo colapsa de tráfico rodado, y de luces que destellan a cualquier hora del día y de la noche. Mientras el número de pilares de hormigón y tirantes metálicos destruyen la pureza de la tierra y su geología más profunda.

Fuente: Elaboración propia. 
El puente se erige sobre los fondos arenosos de la ría y genera un sinfín de impactos y daños, tanto al medio acuático como aéreo y terrestre. De manera constante degrada los ecosistemas marinos, a causa de la descomposición diaria de sus materiales, suponiendo incluso un peligro para la salud humana -al consumir el marisco o el pescado procedente de sus aguas-, suponen un incremento continuo y constante de las emisiones procedentes de los gases efecto invernadero de los vehículos que transitan por sus vías -amén de los desechos que se lanzan por las ventanillas de los coches-, aumentan los accidentes de tráfico así como la intensidad de la contaminación acústica (originada tanto por el ruido producido por el tráfico rodado como por el choque continuo del viento sobre los "tirantes", especialmente, en las épocas donde el viento es más intenso, como vimos anteriormente), y, del mismo modo, suponen un más que considerable riesgo para la flora marina y la fauna acuática y terrestre, especialmente, la de las aves nocturnas que ven alterados sus hábitos de vida y ven incrementado sus niveles de estrés, entre otras cuestiones (Figura No 14).

Por lo que debemos tener presente que, dichas obras de ampliación y mejora del puente y del "corredor", provocan la anexión de elementos y factores en un territorio, como hemos señalado, complejo, en el que el uso de dinamita, la degradación del suelo -por presión y por los procesos de aplanamiento de la tierra-, la tala de vegetación, la destrucción de hábitat, los cambios en los drenajes, los procesos de cambio de modelos económicos, la desmembración de la montaña, etc., se consolidan como potenciadores de destrucción del medio y de su entorno, condicionando y repercutiendo tanto en los ecosistemas como en las dinámicas poblaciones y las actividades económicas. Por lo que, con todo ello, podemos concluir que el impacto ambiental de las infraestructuras del "corredor" se concretan en una vulnerabilidad de los ecosistemas de la península del Morrazo que, sin lugar a dudas propician tales niveles de riesgo para el entorno y una amenaza real para el medio que pueden llegar, incluso, a desaparecer.

\section{Conclusiones}

Los denominados "riesgos antrópicos" vinculados a planes y proyectos orientados a la construcción de infraestructuras, cobran una más que notable importancia en los procesos de concreción y elaboración de nuevos modelos de desarrollo; que coadyuven a un progreso económico, ecológico y social, en territorios complejos, tanto por su realidad geográfica como por la legislación vigente, y, la aplicación que de esta se hace. A lo largo de la presente investigación se porne de manifiesto la enorme importancia que tiene la aplicación de las metodologías de la "evaluación ambiental", tanto en el inicio, como en el final del proceso y desarrollo del proyecto, del programa, del plan e, incluso, de las políticas. En nuestro caso concreto, del Proyecto. Y no puede servir de excusa que sea una ampliación de una estructura ya realizada. Ello entrañaría un fracaso ex-antes que se acaba manifestando ex-post. De este modo, se nos muestra como, ni la "evaluación de Impacto Ambiental" ni la denominada "declaración ambiental", no consiguen controlar, reducir, mitigar o frenar los impactos, daños o amenazas a las que se ve expuesto un medio físico vulnerable y frágil, y sus consecuencias sobre su medio humano y económico, tal y como sucede en el llamado "corredor del Morrazo" (principal aportación realizada en nuestro estudio).

Y, es que, todas las decisiones económicas tienen implicaciones ambientales, constatando que las "externalidades" impregnan todo el sistema económico; la denominada "evaluación de 
impacto ambiental" se nos muestra como un cierto significado que trasciende a la mera caracterización jurídica, y administrativa, ya que en el desarrollo de sus determinadas etapas, suelen interponerse e influir fuertes implicaciones de carácter político. De este modo, los procesos de desdoblamiento del llamado "corredor del Morrazo", hasta su conversión en autovía, suponen una enorme presión sobre el medio; se generan procesos de contaminación -atmosférica, acuática, lumínica o acústica-, que degradan de manera continuada e irreversible el suelo, la vegetación, la fauna,..., y, a largo plazo, merman la calidad de vida de una población que, en apariencia, se beneficia de unas obras de ampliación viaria-; a esto añadir la especulación que de estas obras dimanan, que tiene por objeto la recalificación de suelo para la construcción de viviendas unifamiliares dispersas por los valles de las montañas, que permitan afrontar los procesos de expansión de la urbe viguesa, y, por ende, degradando y destruyendo aún más el entorno en el que se asientan y por el que discurren dichas infraestructuras (su estudio y valoración es una de nuestras principales líneas de investigación, presente y futura).

\section{Referencias bibliográficas}

ATLANTICO.NET. La autovía del Morrazo ya tiene plan definido. 06/01/2017. Atlántico.net.

BARTON, J.R. e IRARRÁZAVAL, F. Adaptación al cambio climático y gestión de riesgos naturales: buscando síntesis en la planificación urbana. Revista de Geografía Norte Grande, 2016, № 63, p. 87-110.

DANCEY, R and LEE, N. A comparison of the quality of environmental impact statements in Ireland and the UK. Environmental Management Ireland, 2003, No 1 (2), p. 21-26.

DIARIO OFICIAL DE GALICIA (DOG Núm. 158), del jueves 16 de agosto del año 2001.

GONZÁLEZ GARCÉ, A. "at alii". La ría de Vigo. Una aproximación integral al ecosistema de la ría de Vigo. Instituto de Estudios Vigueses, 2008.

HSU, A. "et alii". The 2014 Environmental Performance Index. Yale Center for Environmental Law \& Policy., New Haven, 2014.

ICEACSA. Proxecto de Trazado e Impacto Ambiental: Variantes de Cangas e Moaña. 2016.

KLEINSCHMIDT, V. Bodenschutz-belange bei der UVP in Raumordnungsverfahren (Beispiel Femstrassenplanung in NRW) Dortmunder Vertrieb für Bau-und Planungsliteratur. Dortmund, Germany, 2013.

KOBUS, D. and LEE, N. The role of environmental of extractive industry projects. Projects Appaisal, 1993, No 8, Vol 3.

MAPFRE. Riesgo y seguro en "la construcción de Infraestructuras civiles". Madrid., Edt. MAPFRE., 2003. 
MARTínEZ, A. y PÉREZ, A. (coord.). Atlas climático de Galicia. Xunta de Galicia, 1999.

PARKIN, J. Judging Plan and Projects. Avebury. London, U.K., 1993.

PHANEUF, Y. EIS Process and Decision Making., Canadian Environmental Assessment Research Council. Hull, Québec, 2010.

POLGALICIA. Plan de Ordenación do litoral de Galicia, 2011.

ROY, B. Méthodologie Multicritère d'Aide à la Décision. Economica, Paris., 2015

SOTELO NAVALPOTRO, J.A. Riesgos naturales y tecnológicos en España, hoy. Observatorio medioambiental, 2008., No 11, pp. 9-12.

SOTELO NAVALPOTRO, J.A.; SOTELO PEREZ, M.; GARCIA QUIROGA, F. "Consequiences for the Natual Heritage and Cultural Significance of the Current Patterns of Development in the Coastal Region of the Mediterranean Sea". International Journal of Business and Social Science. 2016.,Vol. 7 n० 4. Estados Unidos, ISSN 2219-1933

SOTELO PÉREZ, M. y SOTELO PÉREZ, I. Una aproximación al marco teórico de los riesgos. Observatorio Medioambiental, 2017, vol. ${ }^{\circ 7}$, pp. 9-36.

TOLÓN BECERRA, A.; LASTRAS BRAVO, X. SOTELO NAVALPOTRO, J. A. "Territorial distribution of transport emission reduction targets from an environmental, economic and social viewpoint". Environmental Science and Policy, 2012. vol. 16, pp. 97-113

UNITED NATIONS ECONOMIC COMISSION FOR EUROPE. Application of Environmental Impact Assessment Principles to Policies, Plans and Programmes. United Nations Economic Comission for Europe, 2012, Geneva., Switzerland, 89 pp.

VINCKE, PH. Multicriteria Decision-Aid. John Wiley and Sons, Chichester, 2002.

XUNTA DE GALICIA. DOC. 23 de abril del 2014., Agencia gallega de infraestructuras., Declaración de Impacto Ambiental. Variante Cangas y Moaña (Pontevedra).

WOOD, C. and JONES, C.E. Monitoring Environmental Assessment and Plannig, London., HMSO, 2011. 